\title{
The Role and Place of Cities in the Knowledge-Based Society and Economy (A Case Study of Iran)
}

\author{
Jamal Mohammadi ${ }^{1}$, Aboozar Bakhshi ${ }^{1} \&$ Houshang Bashiri ${ }^{2}$ \\ ${ }^{1}$ Geography and Urban Planning, University of Isfahan, Isfahan, Iran \\ ${ }^{2}$ Physiography (Climatology in the Environmental Planning), Payam Noor University of Urmia, Urmia, Iran \\ Correspondence: Aboozar Bakhshi, Geography and Urban Planning, University of Isfahan, Isfahan, Iran. Tel: \\ 98-913-729-8477. E-mail: aboozar.bakhshi@gmail.com
}

Received: March 12, 2016

Accepted: May 25, 2016

Online Published: July 17, 2016

doi:10.5539/res.v8n3p197

URL: http://dx.doi.org/10.5539/res.v8n3p197

\begin{abstract}
This article considering the interrelationships between knowledge and Urban Development. An Overview is of complementary views, such as knowledge-based cities, learning cities, intelligent cities and creative cities. There are four main channels whereby cities join the knowledge society: human capital, economic structure, innovation systems, information and communication technology. On this basis provinces of Iran are subjected to a comparative analysis of their knowledge indicators in each of these four components. The study is descriptive-analytical and practical in terms of objective. For comparative analysis, 31 provinces of Iran and 55 indexes were selected based on knowledge. Use was made of Shannon Entropy to measure relative importance and weight of each index. Also, usingmulti-attribute decision making methods of TOPSIS and VIKOR to rank provinces and cluster analysis was used to classify. Finally, using the software Arc GIS, map of the provinces benefit levels were drawn. Research findings showed that using TOPSIS method the benefit rate of provinces in Iran from the indexes of knowledge-based society and economy and rank of each province in different indexes represented a high loss of imbalance in the how distribution of these indexes in the provinces of the country. According to this, Tehran province was considered as the highest benefit province and is ranked 1on all four indexes of human capital, economic structure, innovation and ICT systems with values (priority factor) 0.941, $0.741,0.8206$ and 0.752 , respectively. In contrast, provinces of South Khorasan in "human capital" index with value 0.009 , Ilam in "economic structure" index with value 0.140 , Kohgiloyeh-Buyerahmad in "innovation systems" index with value 0.024 , and North Khorasan in "information and communication technology" index with value 0.062 were identified as the lowest benefited provinces. Using TOPSIS and VIKOR methods, assessment of the province's position in knowledge-based society and economy suggests that in the TOPSIS method, Tehran was recognized as the highest benefit province with value 0.740 and Ilam was considered as most deprived benefit province with value 0.069. But in the VIKOR method, Isfahan was identified as highest benefit province with value 1.129 while Ilam was determined as the most deprived benefit province with value 0.627. According to the scores obtained from the above methods, through density-based hierarchical cluster analysis method, the country provinces have been classified into 3 equal groups. On this basis, Tehran province was at the highest benefit level in cluster 1, Isfahan, Khorasan Razavi, East Azerbaijan, Fars and Khuzestan were at the half benefit levels in cluster 2 and the other 25 provinces were at the lowest levels of knowledge-based society and economy in cluster 3 . Results of classification of provinces showed that the country provinces were located in the heterogeneous and unbalanced conditions. The overall results showed that not a significant proportion of Iranian provinces have been introduced in the process of joining knowledge-based society and economy.
\end{abstract}

Keywords: knowledge-based society, knowledge-based economy, urban development, MADM, TOPSIS, VIKOR, shannon entropy, cluster analysis, Iran 


\section{Introduction}

One of the concepts that endeavours to describe the recent evolution of certain societies and territories, and also to steer collective objectives aimed at achieving a better position in the current context of globalization, is the concept of the knowledge society and economy.

In the last two decades of the 20th century, the importance given to the Information and Communication Technology (ICT) revolution brought the concept of the information society into prominence. Also stressed with this concept were the information society's function as the necessary infrastructure for the construction of a network society and the birth of a new information economy associated with the new technological paradigm, not to mention its many ways of having an impact on societies and their territories in such wide-ranging areas as culture, employment, mobility and consumer habits (Webster, 2002).

In the last decade this concept has been gradually replaced by another, more inclusive, less technologically biased concept, the knowledge society. This concept used it to describe above all economic and labour-related transformations, yet to indicate also the effects such transformations have on society and power relationships.

At present the term identifies all societies where the production, dissemination and application of diverse forms of knowledge to improve competitiveness, quality of life and sustainability are made a top-priority objective (David \& Foray, 2002).

Thus, new forms of inequality among territories appear depending on different territories' supply of resources and connection to the main channels through which strategic knowledge circulates. Such forms of inequality create an important digital gap, but they also create a cognitive gap, between countries as well as between regions or cities (Isaksen \& Onsanger, 2010). In every case cities are regarded as privileged places for concentrating knowledge resources and promoting creativity and innovation (Jacobs, 1961). However, there clearly are considerable differences between cities, in terms of which cities have these types of resources and the capacity to come up with innovative responses. Such differences cannot be explained by city size alone (Mendez \& Moral, 2010).

Working from this theoretical context, this article proposes a twofold objective: first, it endeavors to establish a precise definition of the meaning given here to the concept of the knowledge-based city, as compared with the current spate of terms concerning the interrelationships between knowledge and urban development.

The second part of the text concerns comparative analysis of the 31 provinces of Iran. For this purpose, 55 indexes were selected based on knowledge and relative importance and weight of each index was determined based on the Shannon Entropy. Further, for ranking the provinces a multi-attribute decision making methods TOPSIS and VIKOR are used and for their classification use was made of cluster analysis. Finally, taking advantage of the software Arc GIS, map of provinces benefit levels was drawn.

\section{Theoretical Debates}

\subsection{Knowledge-Based Economy}

From the OECD (Note 1) point, economic knowledge-based economy is directly based on the production, distribution and consumption of knowledge and Information is formed (OECD, 2001). In the knowledge-based economy, knowledge is main driving of growth, wealth creation and employment in all fields of activities and over traditional factors such as labor and capital leads generated. Based on this definition, the knowledge-based economy not only depends on a limited number of advanced technology-based industries, but all economic activities is based on the knowledge; even regarding such as mining and agriculture. As well as the knowledge required for the knowledge-based economy, making it not only the kind of sheer and includes the knowledge of cultural, social, and management (Vahidi, 2001). In the knowledge-based economy economic structures generally does it change and the sectors associated with the production, distribution and consumption of information and knowledge, namely research and development, training and production technology, the importance of the finds. This is while the sectors associated with the production, distribution and consumption of raw materials as well as physical capital relative importance of gradually lose their (OECD, 1996).

\subsection{Cities in the Knowledge-Based Society and Economy}

The initial discussion about the emerging knowledge-based society and economy serves as a frame for the current debate about the performance of cities in the present context of globalization and the different capacities for generating creative responses based upon the local knowledge stock that allow an increase of the innovation rate. 
In the final decade of the 20th century, starting with Castells' pioneering reference (1991) to the informational city, new names focused their attention on the ICT revolution's impact on both the socioeconomic base of cities and the internal morphology or external relations of cities. That emphasis on digital infrastructure, high-tech industrial sectors and advanced services was also linked to the rise of urban forms characteristic of the new era, thus originating a lengthy list of terms such as telecity, flexicity, cyberville, wired city and digital city.

In the present decade these terms are being replaced by others that seek to identify the cities that have shown a greater capacity to generate or incorporate knowledge and translate it into different forms of innovation, both in terms of economics and business and in terms of society and local institutions. Such cities are true innovative territories and are making progress towards forms of development not limited to the economic (Mendez \& Moral, 2010).

In 2000, the collective work of the GREMI Group, drawing inspiration from the theory of the milieu innovateur, stressed the special presence of this type of city environment, which is constituted above all by innovative, networked small and medium-sized enterprises (Crevoisier \& Camagni, 2000). In parallel, the transposition of innovation system theory to the urban scale popularized the concept of the learning city. This focused attention on the important role of companies, institutions that undertake and transfer R \& D, universities and governments in the fostering of innovation, with a tendency to cluster in certain regions and cities, translated into tangible results (OECD, 2001). Since then, it can be said that new concepts have been appearing almost annually to modify the attention paid to the different manifestations of the interrelationship between knowledge and urban development, as well as the best type of indicators for measuring them.

The first concept is that of the intelligent city, whose foremost exponent is Komninos $(2002,2006)$. Another very close concept is the idea of the knowledge-based city, used by diverse authors, from the pioneering work of Knight (1995) to work such as that done by Van Winden et al. (2007). But perhaps the most widely disseminated and controversial is the term creative city, proposed by Hall (2000) but popularized especially by Florida (2002a, 2005), as the spatial embodiment of the influence ascribed to the so-called "creative classes" in the new dynamics of urban development. Also in recent years, the work of Jones et al. (2006) on the ideopolis, the work of Cortright and CEOs for Cities (Cortright, 2006) on city vitals and the work of Tusnovics (2007) on the cognitive city have contributed a number of nuances to what was already known, by pointing out new components in the definition of "urban intelligence" (Mendez \& Moral, 2010).

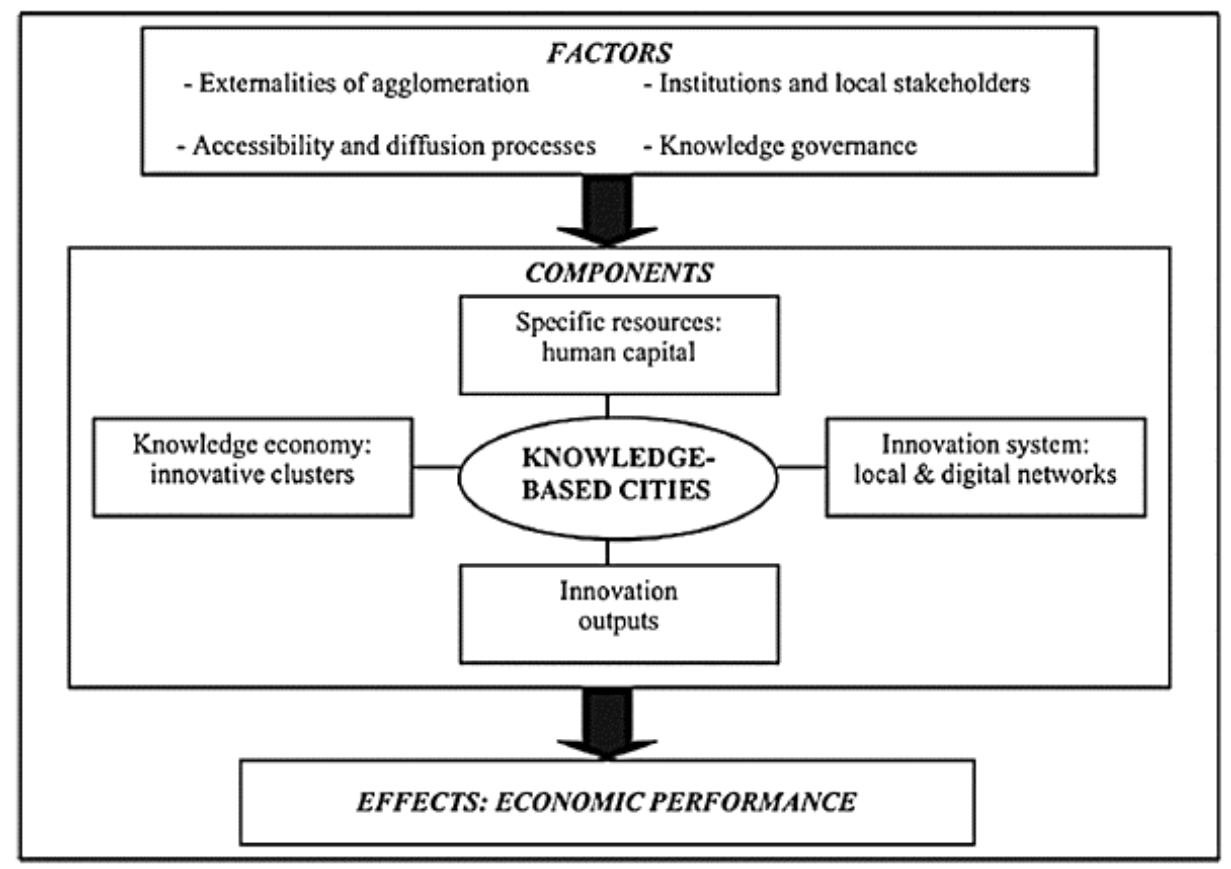

Figure 1. The construction of knowledge-based cities: factors, components and effects (Map 1) Resource: Mendez \& Moral, 2010. 
According to the theoretical literature review, the meaning assigned to the concept of the knowledge-based city, on the basis of the four types of components that best define it, as follows: (i) a stock of specific resources for the generation and application of knowledge, the foremost such resource being human capital; (ii) an economic structure in which knowledge-intensive sectors and companies hold a leading place; (iii) an innovation system based on networking among local and regional stakeholders, plus an underlying digital infrastructure to facilitate the interactive exchange of information and knowledge; (iv) tangible results in the form of economic and social innovations (Figure 1).

\section{The Studied Scope}

Iran between 25 and 40 degrees north latitude and between 44 to 64 degrees east longitude located. It covers an area of 1,648,195 square kilometers of the South West Asia that in the East to Afghanistan and Pakistan, in the north-eastern Turkmenistan, in the north central part of the Caspian Sea, in the north-west of Azerbaijan and Armenia, in the West Turkey and Iraq, and on the south by the Persian Gulf and Oman Sea neighbors.

Table 1. Physical division of the Iran provinces in 2011

\begin{tabular}{|c|c|c|c|c|c|}
\hline Province & Population & Percent & Area $\left(\mathbf{K m}^{2}\right)$ & Percent & Net density \\
\hline The whole country & 75149669 & 100 & 1628750 & 100 & 46.14 \\
\hline East Azarbaijan & 3724620 & 4.96 & 45650 & 2.80 & 81.59 \\
\hline West Azerbaijan & 3080576 & 4.10 & 37411 & 2.30 & 82.35 \\
\hline Ardabil & 1248488 & 1.66 & 17800 & 1.09 & 70.14 \\
\hline Isfahan & 4879312 & 6.49 & 107029 & 6.57 & 45.59 \\
\hline Alborz & 2412513 & 3.21 & 5124 & 0.32 & 470.83 \\
\hline Ilam & 557599 & 0.74 & 20133 & 1.24 & 27.70 \\
\hline Bushehr & 1032949 & 1.38 & 22743 & 1.40 & 45.42 \\
\hline Tehran & 12183391 & 16.21 & 13690 & 0.84 & 890 \\
\hline Chaharmahal-Bakhtiari & 895263 & 1.19 & 16332 & 1 & 54.82 \\
\hline South Khorasan & 662534 & 0.88 & 95385 & 5.86 & 6.95 \\
\hline Khorasan Razavi & 5994402 & 7.98 & 118854 & 7.30 & 50.44 \\
\hline North Khorasan & 867727 & 1.16 & 28434 & 1.75 & 30.52 \\
\hline Khuzestan & 4531720 & 6.03 & 64055 & 3.93 & 70.75 \\
\hline Zanjan & 1015734 & 1.35 & 21773 & 1.34 & 46.65 \\
\hline Semnan & 631218 & 0.84 & 97491 & 5.99 & 6.48 \\
\hline Sistan-Baluchestan & 2534327 & 3.37 & 181758 & 11.16 & 13.94 \\
\hline Fars & 4596658 & 6.12 & 122608 & 7.53 & 37.49 \\
\hline Qazvin & 1201565 & 1.60 & 15567 & 0.96 & 77.19 \\
\hline Qom & 1151672 & 1.53 & 11526 & 0.71 & 99.92 \\
\hline Kurdistan & 1493645 & 1.99 & 29137 & 1.79 & 51.26 \\
\hline Kerman & 2938988 & 3.91 & 180726 & 11.10 & 16.26 \\
\hline Kermanshah & 1945227 & 2.59 & 24998 & 1.54 & 77.82 \\
\hline Kohgiloyeh-Buyerahmad & 658629 & 0.88 & 15504 & 0.95 & 42.48 \\
\hline Golestan & 1777014 & 2.36 & 20367 & 1.25 & 87.25 \\
\hline Gilan & 2480874 & 3.30 & 14042 & 0.86 & 176.68 \\
\hline Lorestan & 1754243 & 2.33 & 28294 & 1.74 & 62 \\
\hline Mazandaran & 3073943 & 4.09 & 23842 & 1.46 & 128.93 \\
\hline Markazi & 1413959 & 1.88 & 29127 & 1.79 & 48.55 \\
\hline
\end{tabular}




\begin{tabular}{cccccc} 
Hormozgan & 1578183 & 2.10 & 70697 & 4.34 & 22.32 \\
Hamedan & 1758268 & 2.34 & 19368 & 1.19 & 90.78 \\
Yazd & 1074428 & 1.43 & 129285 & 7.94 & 8.31 \\
\hline
\end{tabular}

Source: Statistical Center of Iran, 2011, p. 55.

According to the latest political divisions in 2012, Iran has 31 provinces, 422 townships, 1041 districts, 1224 cities and 2566 rural districts (Iran Statistical Center, 2012, p. 49). The highest population density is in between the provinces of country belonging to Tehran province with 890 and the lowest density is belonging to Semnan province with 6.5 person per square kilometer.

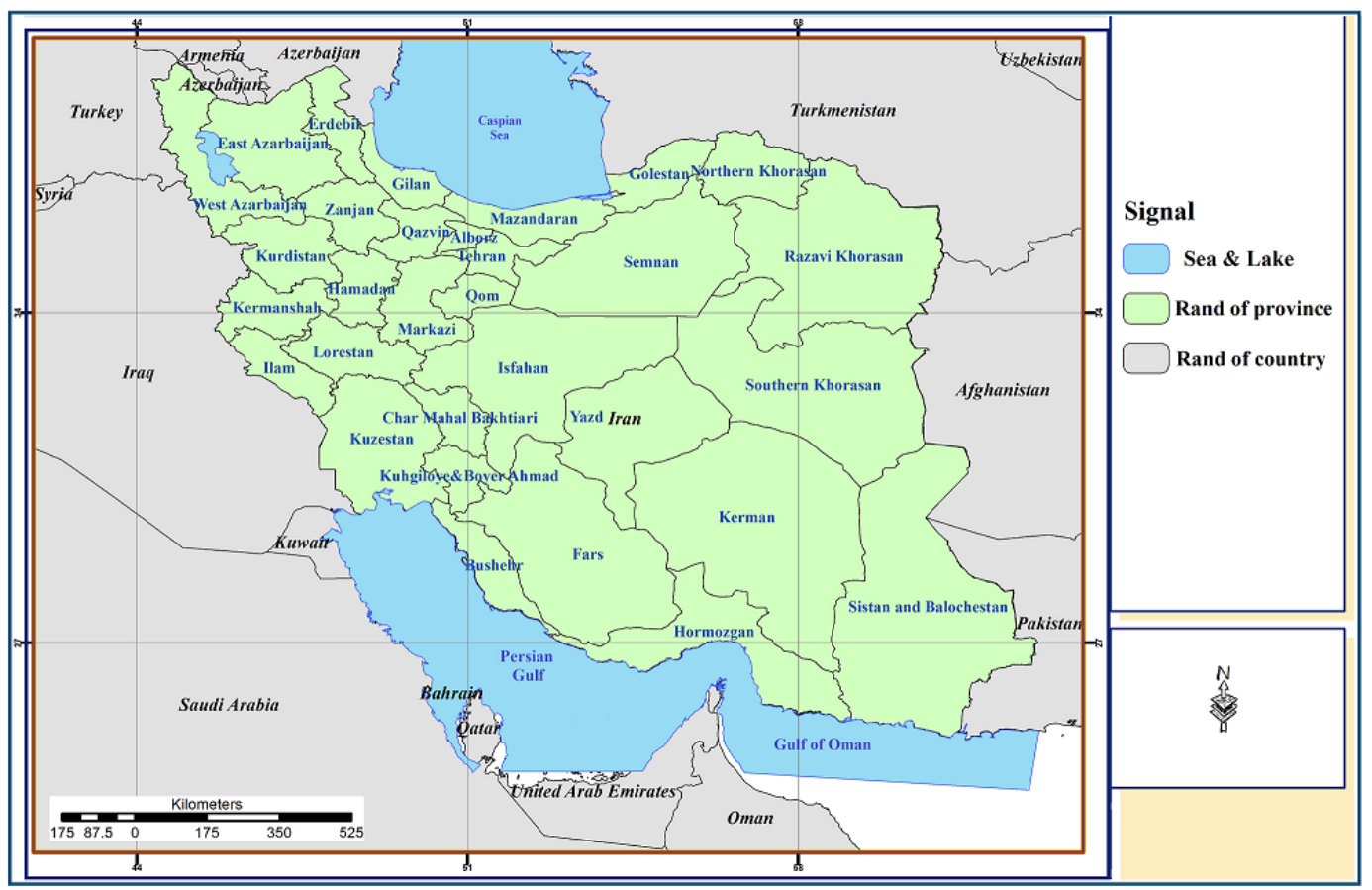

Figure 2. Location of the study area

\section{Research Methodology}

In the present study, methodology is descriptive-analytical and practical type in terms of objective. The population is comprised of 31 provinces of Iran based on division in 2011. On the basis of 55 indexes, provinces were divided into four components of "basic human capital", "economic structure", "and innovation system" and "information and communication technology" and then these four were compared. In a preliminary analysis, the absolute value of indexes is used to measure density as variables of interest in each province. Then, in the original analysis, the criteria have been applied in the form of their relative form (e.g., the percentages in term of the working population, etc.).

A six-step method of analysis was used for data processing. This method initiated with descriptive analysis to determine the spatial distribution. Then by the inferential analysis method and methods of standard score (Z-score) and Spearman rank correlation, status of distribution and correlation level and proportion "rank of knowledge-based society and economy indexes" were compared to the "population rank of provinces".

Next, based on the Shannon Entropy, relative importance and weight of each index were determined and for the ranking of provinces multi-attribute decision making methods of TOPSIS and VIKOR were used and for the provinces classification is used the cluster analysis; finally, taking advantage of the software Arc GIS, map of provinces benefit levels was drawn. 
Table 2. Indexes knowledge-based economy and society

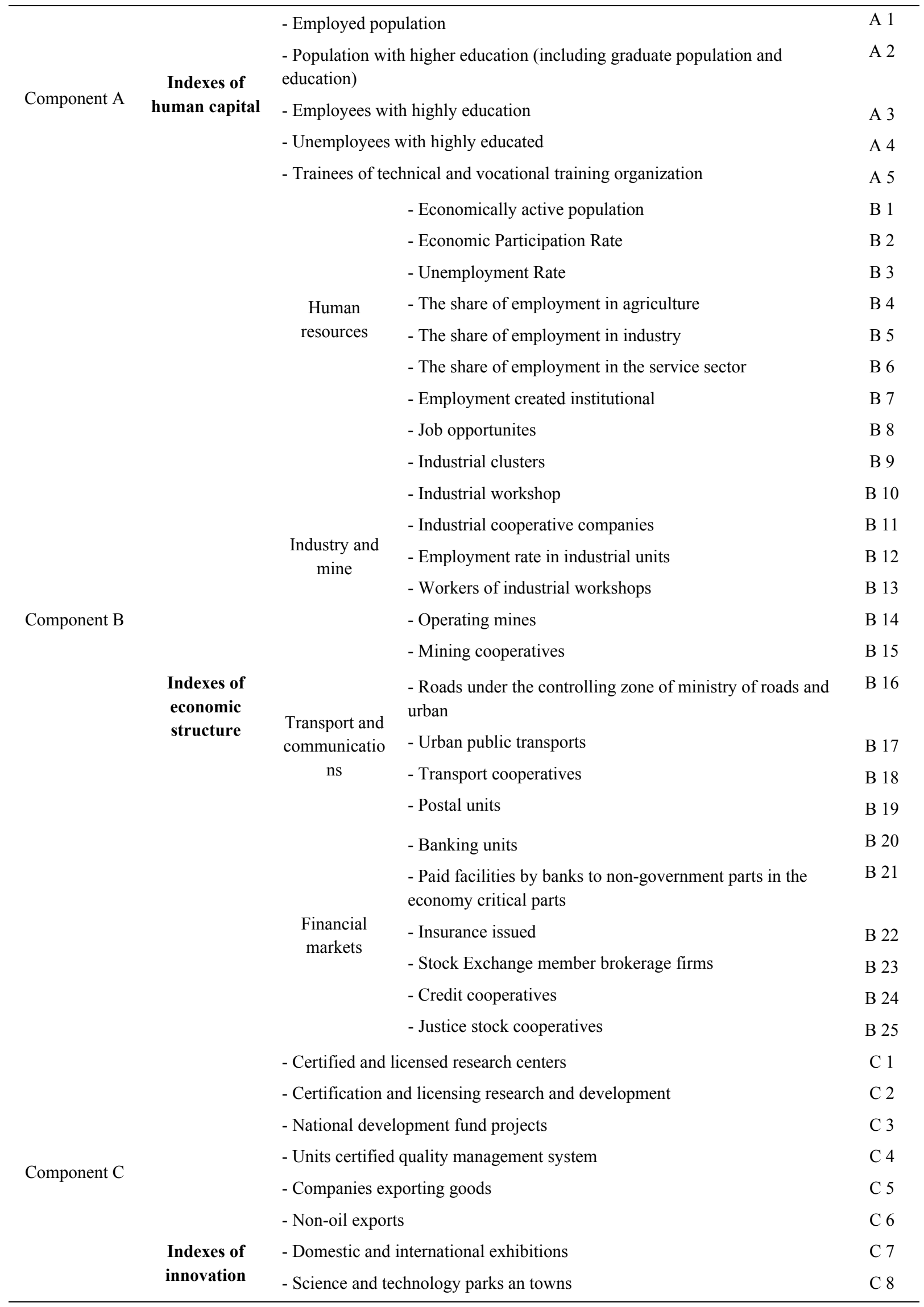




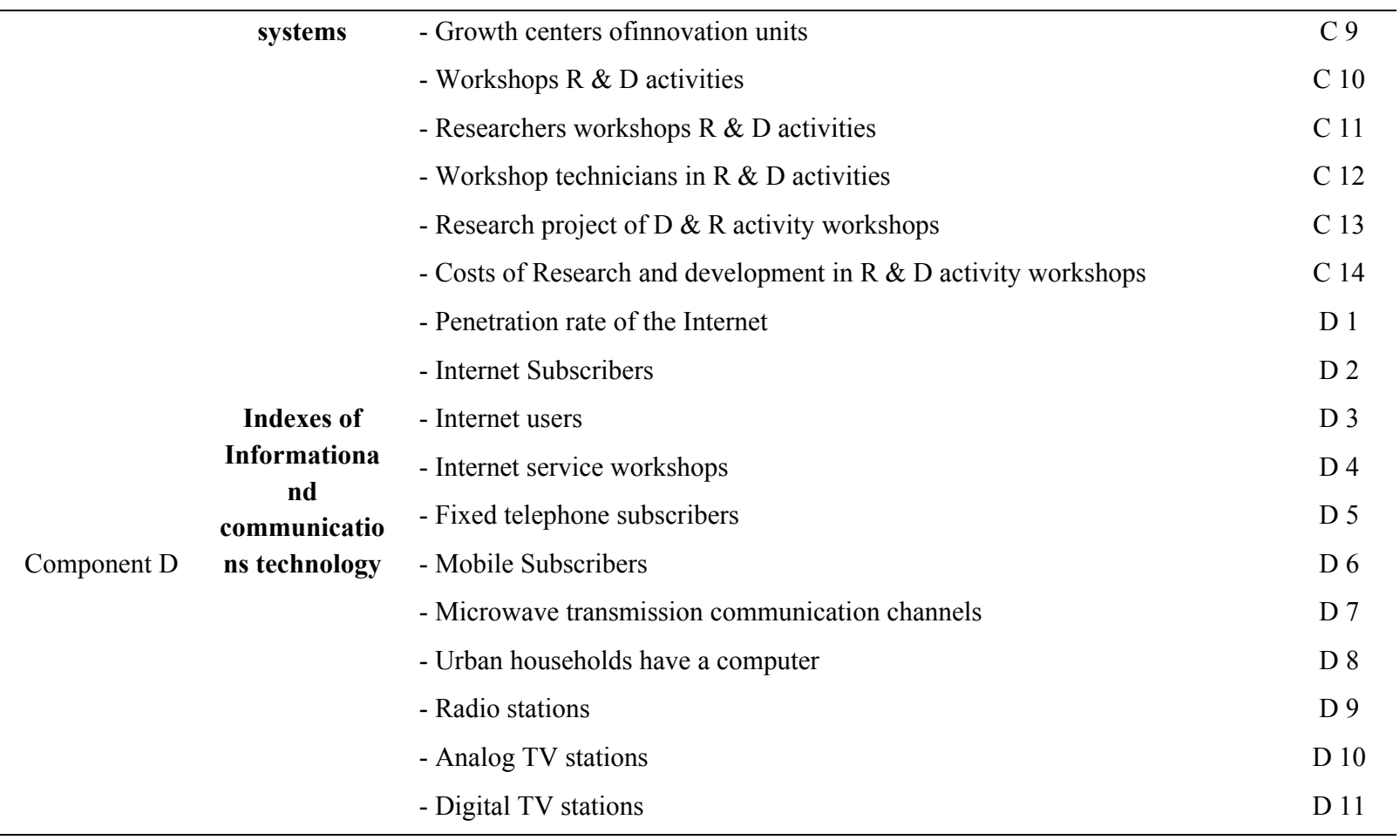

Source: Statistical Centre of Iran, 2011, and Authors, 2015.

Shannon Entropy method: Entropy is a statement of the amount of uncertainty in a continuous probability distribution. The main idea of this approach is that the distribution of values for each index is more, it is more important index (Asgharpour, 2006). The information content of the matrix is first calculated and then $\mathrm{Ej}$ Decision of the determined result. Uncertainty or degree of deviation of each criterion (dj) less the value of $\mathrm{Ej}$ achieved the number one, and finally determine weight each criterion by the function (Bashir et al., 2011).

TOPSIS method: This is a very strong technique compensatory multi-criteria decision-making, to prioritize the options by liken to the ideal answer that to the weighting technique, sensitive however, responses from the profound changes not. In this method, $\mathrm{m}$ option by $\mathrm{n}$ indexes assessed, the option chosen should be the shortest distance to the ideal solution Positive (best, $\mathrm{Ai}+$ ) and the maximum distance to the ideal solution negative (worst-case scenario, Ai-). It is assumed that satisfaction the index has been steadily increasing or reduced (Nastaran, 2009, p. 90).

VIKOR method: This method is used to rank different options and to solve the problem of inappropriate criteria (different units of measurement) and conflicting focus. In this model has several options. There are various options on the basis of several criteria independently evaluated and ultimately choices based on value, ranking them (Sayadi et al., 2009, p. 2258).

Cluster analysis method: This method is one of the main methods for classification of regions, towns, villages; That allows the researcher on the basis of homogeneity among the issues studied, classified them into suitable methods and to interpret and explain their results. General algorithms used in hierarchical cluster analysis method and cluster into two categories: non-hierarchical clustering method can be divided. Hierarchical clustering method has a hierarchical tree structure that is done to the two modes of compression and resolution (Kalantari, 2008, p. 229). 


\section{The Main Findings}

\subsection{Knowledge-Based Economy in Iran}

World Bank Knowledge Assessment Methodology (KAM) has variables that shows four fundamental pillar of the knowledge-based economy that include having overall economic performance, Economic Incentive and Institutional Regime (including Economic Regime and governance), the innovation system (including education, labor, and gender) and Information and Communications Technology (ICT).

Ranking of world economies by the World Bank in 2012, based on these Indexes, Iran is ranked 94 (World Bank, 2012). Table 3 show's the knowledge-based economy in Iran.

Table 3. In the knowledge-based economy-2012

\begin{tabular}{|c|c|c|c|c|c|c|c|}
\hline Indexes & $\begin{array}{l}\text { Index of } \\
\text { knowledge } \\
\text {-based } \\
\text { economy }\end{array}$ & $\begin{array}{c}\text { Index of } \\
\text { knowledge }\end{array}$ & $\begin{array}{l}\text { Economic } \\
\text { Incentive\& } \\
\text { Institutional } \\
\text { Regime }\end{array}$ & $\begin{array}{c}\text { Educatio } \\
\mathrm{n}\end{array}$ & Innovation & $\begin{array}{c}\text { Information } \\
\text { \&communicatio } \\
\text { ns technology }\end{array}$ & $\begin{array}{c}\text { Rank } \\
\text { ing }\end{array}$ \\
\hline $\begin{array}{c}\text { Rate } \\
\text { (percent) }\end{array}$ & 3.91 & 4.97 & 0.73 & 5.02 & 4.61 & 5.28 & 94 \\
\hline
\end{tabular}

Source: KAM 2012 (http://www.worldbank.org).

\subsection{Determine the Spatial Distribution of Indexes in the Provinces of Iran through Descriptive Analysis}

In order to provide an estimate description of the amount and method which provinces of Iran by that into society and knowledge-based economy, survey to the distribution of relative indexes (Figure 3). 


\begin{tabular}{|c|c|c|c|c|c|c|c|c|c|c|c|c|c|c|c|c|}
\hline 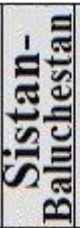 & 를 & 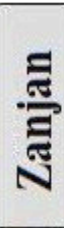 & 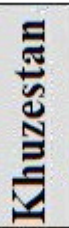 & 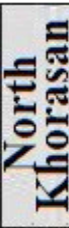 & 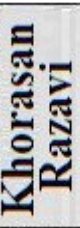 & 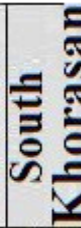 & 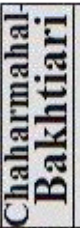 & 를 & $\frac{3}{a}$ & $\underset{\Xi}{\Xi}$ & $\stackrel{N}{2}$ & 를 & $\frac{\overrightarrow{2}}{2}$ & & 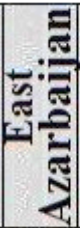 & $\stackrel{0}{0}$ \\
\hline 1.88 & 0.88 & 49 & 4.65 & 1.25 & 8.42 & 1.02 & 1.17 & 17.09 & 1.62 & 0.71 & 3.24 & 6.80 & 1.73 & 4.09 & 5.49 & A1 \\
\hline 1.47 & 1.16 & 1.27 & 5.19 & 0.89 & 63 & 0.80 & 1.10 & 23.84 & 1.35 & 0.96 & 1.12 & 7.60 & 1.51 & 2.98 & 4.62 & A2 \\
\hline 1.52 & 1.08 & 29 & 4.76 & 0.95 & 87 & 0.91 & 1.05 & 24.36 & & 0.89 & 3.86 & 6.88 & 1.52 & 2.89 & 4.45 & A3 \\
\hline 1.05 & 0.74 & 05 & & & .74 & 0.48 & 1.11 & 19.97 & & & 5.07 & 7 & 1.89 & 2.67 & 4.40 & A4 \\
\hline 4.55 & 1.07 & 25 & & 0.71 & 20 & 1.12 & 1.69 & 3.07 & 1 & & 0.64 & 21.86 & 6.56 & 2.47 & 2.36 & A5 \\
\hline 2.26 & 0.83 & 43 & & 1.19 & 7.92 & 0.93 & 1.19 & 16.76 & & & 3.31 & 6.69 & 1.73 & 3.97 & 5.19 & B1 \\
\hline 2.29 & 2.98 & 65 & & 3.32 & 3.20 & 3.34 & 3.22 & 3.16 & .99 & .24 & .34 & 3.48 & 3.73 & 3.68 & 3.49 & B2 \\
\hline 2.62 & 2.72 & 22 & & 3.20 & 2.40 & 2.22 & 3.51 & 2.9 & & 4.15 & 5.10 & 3.49 & 3.35 & 3.43 & 2.32 & B3 \\
\hline 3.69 & 1.86 & 12 & & 5.72 & & 4.65 & 3.15 & & & & 0.46 & .65 & 1.22 & 5.42 & 2.92 & B4 \\
\hline 3.50 & 85 & & & & & 41 & 4.24 & & & & & .98 & 0.74 & 2.46 & 4.25 & B5 \\
\hline 2.99 & 3.59 & & & & & 2.61 & 2.71 & & & & & & 0.46 & 2.92 & 2.80 & B6 \\
\hline 3.04 & 1.42 & 28 & & 2.26 & & 93 & 1.17 & & & & .04 & & .20 & 4.03 & 6.17 & B7 \\
\hline 0.33 & 2.12 & & & & & 2 & 0.54 & 2 & & & 4.52 & & .82 & 2.83 & 7.08 & B8 \\
\hline 5.88 & 6 & & & & & 54 & 0.54 & & & & & 3.37 & .07 & 3.74 & 6.42 & B9 \\
\hline 0.88 & 439 & & & & & & 0.78 & 17.8 & & & .16 & 5.68 & 0.97 & 3 & 6.04 & B10 \\
\hline 1.73 & 1.73 & & & & & & 3 & & & & & & .10 & 2.24 & 6.45 & B11 \\
\hline 0.69 & 3 & & & & & & 1.21 & 10. & & & & .15 & 10 & & 7.14 & B12 \\
\hline 0.32 & 2.81 & & & & & 43 & 0.71 & 21.4 & 1 & & 7.69 & 1.41 & .71 & & 4.95 & B13 \\
\hline 1.58 & & & & 2 & & & 3.42 & 2.7 & & & & & .95 & & 5.47 & \\
\hline 0.86 & & & & & & & 0.78 & 22.0 & & & & & 0.69 & 2.07 & 3.10 & \\
\hline 7.26 & & & & & & & 1.39 & & & & & & & & 2.96 & B16 \\
\hline 2.60 & 1.56 & & & & & & 1.69 & & & & & & .28 & & & \\
\hline 4.25 & & & & & & & 1.10 & & & & & & 56 & & & B18 \\
\hline 1.8 & 2.0 & & & & & & 1.75 & & & & & & 05 & & 7.39 & B19 \\
\hline 2.23 & & & & & & & 1.48 & & & & & & 56 & & 3.94 & B20 \\
\hline 0.52 & & & & & & & 0.82 & & & & 0 & & 93 & & 3 & B21 \\
\hline 1.2 & & & & & & & 0.65 & & & & & & .23 & & 3.98 & \\
\hline 0.5 & 72 & & & & & & 0.18 & & & & 8.48 & & 1.26 & 5 & 4.87 & B23 \\
\hline 2.49 & & & & & & & 3.90 & & & & & & .01 & & 4.13 & B24 \\
\hline 2.92 & 1.1 & & & 1.75 & & 2.05 & 1.75 & & & 2.34 & 0.88 & & 2.63 & 48 & 5.56 & B25 \\
\hline 0 & & & & 0 & & & 0 & & & & & & 0 & & 04 & $\mathrm{C} 1$ \\
\hline 0 & & & & & & & & & & & & & & & 2.70 & $\mathrm{C2}$ \\
\hline 0 & & & & & & & & & & & & & & & & $\mathrm{C3}$ \\
\hline 0.41 & & & & & & & 0.32 & & & & & & & & & $\mathrm{C4}$ \\
\hline & & & & & & & & & & & & & & & & $\mathrm{C5}$ \\
\hline & & & & & & & & & & & & & 0.07 & 2.04 & & C6 \\
\hline 2.12 & & & 4 & & & & 3.41 & & & & & & & 4 & & C7 \\
\hline 0 & & & & & & & 0 & & & 0 & & & v & & & $\mathrm{C} 8$ \\
\hline 3.03 & & & & & & & & & & & & & & & 5.05 & C9 \\
\hline & & & & & & & & & & & & & & & 4.55 & C10 \\
\hline 1.4 & & & & & & & 0.97 & & & & & & & & & C11 \\
\hline & & & & & & & & & & & & & & & & \\
\hline & & & & & & & & & & & & & & & & $\mathrm{C} 13$ \\
\hline & & & & & & & & & & & & & & & 2.71 & $\mathrm{C} 14$ \\
\hline 1.3 & & & & & & & & & & & & & & & 3.56 & \\
\hline & & & & & & & & & & & & & & & & \\
\hline & & & & & & & & & & & & & & & & D3 \\
\hline 1.24 & 1.38 & 1 & & & & & 1.68 & & & & & & 18 & & 5.71 & D4 \\
\hline 1.79 & 1.0 & & & & & & & & & & & & & & 5.28 & \\
\hline & & & & & & & & & & & & & & & & D6 \\
\hline & & & & & & & & & & & & & & & & D7 \\
\hline 0.85 & 1.0 & & & & & & 0.72 & & & & 3.16 & 99 & 16 & & 4.77 & D8 \\
\hline & & & & & & & 1.04 & & & & & & & & & \\
\hline & & & & & & & & & & & & & & & & \\
\hline & 1.7 & & & & & & 3.5 & & & & 0 & & .57 & & 3.57 & D11 \\
\hline 1.94 & 1.99 & 1.91 & & 1.26 & 5.82 & 1.97 & 1.55 & 16.62 & 2.37 & 1.05 & 2.56 & 7.34 & 1.66 & 2.967 & 4.56 & Averag \\
\hline 1.68 & 1.37 & 1.30 & 3.34 & & 2.48 & 2.90 & 1.17 & 13.03 & 3.19 & 1.0 & 2.24 & 4.75 & 1.30 & 1.56 & 1.64 & STDEI \\
\hline
\end{tabular}




\begin{tabular}{|c|c|c|c|c|c|c|c|c|c|c|c|c|c|c|c|}
\hline$\underset{乛}{\mathcal{U}}$ & 를 & 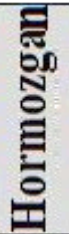 & $\sum^{-1}$ & 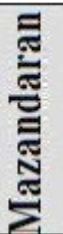 & 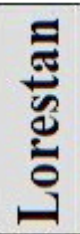 & $\frac{5}{5}$ & 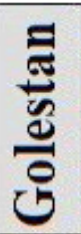 & 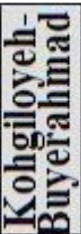 & 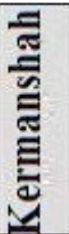 & 를 & 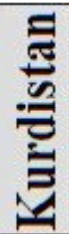 & 릉 & - & 光 & $\stackrel{0}{0}$ \\
\hline 1.57 & 2.41 & 1.96 & 1.99 & 4.62 & 2.07 & 3.70 & 2.40 & 0.72 & 2.30 & 3.68 & 2.04 & 1.38 & 1.65 & 5.98 & A1 \\
\hline 1.78 & 1.97 & 1.47 & 1.82 & 5.10 & 2.14 & 3.33 & 1.92 & 0.98 & 2.31 & .72 & 1.36 & 1.71 & 1.47 & 6.43 & A2 \\
\hline 1.83 & 1.79 & 1.71 & 1.84 & 4.85 & 1.82 & 3.19 & 1.95 & 0.90 & 2.08 & 3.25 & 1.42 & 1.42 & 1.47 & 5.61 & A3 \\
\hline 1.48 & 1.77 & 0.97 & 1.65 & 5.75 & 3.16 & 4.53 & 1.60 & 1.30 & 3.34 & 3.98 & 1.44 & 0.81 & 1.16 & 7.90 & A4 \\
\hline 2.31 & 2.50 & 0.58 & 4.56 & 1.79 & 1.93 & 3.30 & 2.40 & 1.13 & 4.09 & 2.91 & 1.82 & 1.76 & 0.69 & 4.55 & A5 \\
\hline 1.49 & 2.38 & 1.97 & 1.93 & 4.44 & 2.32 & 3.71 & 2.35 & 0.78 & 2.60 & 3.82 & 2.06 & 1.34 & 1.62 & 6.13 & B1 \\
\hline 3.13 & 3.33 & 2.88 & 3.24 & 3.43 & 3.25 & 3.42 & 3.39 & 2.65 & 2.91 & 3.01 & 3.50 & 3.03 & 3.49 & 3.27 & B2 \\
\hline 1.58 & 3.27 & 2.90 & 2.90 & 2.69 & 5.07 & 4.38 & 2.30 & 3.72 & 4.15 & 3.20 & 3.70 & 2.59 & 3.27 & 4.89 & B3 \\
\hline 1.68 & 4.08 & 2.29 & 3.14 & 2.95 & 4.55 & 3.86 & 4.91 & 3.03 & 4.23 & 4.48 & 4.74 & 0.82 & 3.38 & 3.72 & B4 \\
\hline 4.31 & 2.85 & 2.92 & 3.90 & 3.18 & 2.81 & 2.53 & 2.79 & 3.23 & 2.53 & 3.12 & 2.34 & 3.92 & 3.73 & 3.09 & B5 \\
\hline 3.35 & 3.28 & 4.07 & 2.96 & 3.58 & 3.07 & 3.61 & 2.93 & 3.50 & 3.44 & 2.89 & 3.34 & 4.05 & 2.96 & .27 & B6 \\
\hline 1.81 & 3.90 & 3.72 & 2 & 86 & 2.09 & 2 & 1.95 & 0.74 & 65 & .44 & 3.42 & 1.10 & 1.58 & 94 & B7 \\
\hline 8.32 & 2.19 & 0.61 & 1.45 & 4.17 & 0.76 & 1.26 & 2.18 & 0.35 & 0.80 & 2.91 & 0.81 & 5.78 & 3.17 & 5.74 & B8 \\
\hline 2.67 & 3.74 & 1.61 & 3.74 & 5.88 & 0.54 & 3.74 & 1.07 & 2.67 & 0.54 & 2.67 & 2.67 & 3.21 & 2.67 & 2.67 & B9 \\
\hline 3.04 & 1.96 & 0.55 & 4.57 & 3.59 & 0.70 & 3.90 & 1.57 & 0.22 & 1.64 & 1.02 & 1.31 & 3.75 & 2.99 & 3.52 & B10 \\
\hline 3.79 & 1.82 & 3.64 & 2.28 & 7.63 & 3.90 & 3.57 & 5.68 & 1.85 & 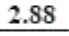 & 4.53 & 1.53 & 0.99 & 1.10 & 4.27 & B11 \\
\hline 4.56 & 1.87 & 1.33 & 4.03 & 4.51 & 1 & 4.22 & 1.35 & 0.35 & 23 & 3.74 & 0.52 & 1.98 & 5.25 & 4.90 & B12 \\
\hline 2.98 & 1.06 & 0.92 & 5.39 & 61 & 0.65 & .63 & 0.83 & 1.61 & 1.10 & 1.54 & 0.39 & 1.68 & 5.15 & 32 & B13 \\
\hline 5.93 & 1.47 & 3.35 & 4.63 & 1.75 & 2.91 & 1.16 & 2.56 & 1.77 & 2.61 & 3.54 & 2.95 & 1.79 & 2.95 & 6.72 & B14 \\
\hline 3.01 & 0.78 & 3.88 & 3.70 & & 12.32 & 1.03 & 0.69 & 1.72 & 1.64 & 7.84 & 0.95 & 4.91 & 0.78 & 3.01 & \\
\hline 3.05 & 1.49 & 10.51 & 1.75 & & 1.62 & 9.68 & 1.20 & 1.09 & 2.27 & 5.41 & 1.59 & 0.59 & 1.25 & 06 & B16 \\
\hline 1.30 & 2.58 & 2.96 & 2.01 & 5.75 & 2.83 & 4.60 & 2.10 & 0.95 & 4.82 & 5.11 & 2.44 & 2.03 & 2.43 & 9.58 & B17 \\
\hline 3.56 & 1.18 & 10.99 & 4.47 & 5.08 & & 3.83 & .72 & 4.21 & & 50 & 2 & 0.34 & .40 & .81 & B18 \\
\hline 1.70 & 3.69 & 2.38 & 1.87 & 4 & 3.21 & 3.13 & 4.96 & 1.73 & .13 & 3.39 & 1.93 & 0.99 & 1.36 & 5.27 & B19 \\
\hline 2.64 & 1.85 & 1.98 & 1.93 & 4.03 & 2.07 & 3.58 & 1.79 & 0.72 & 2.36 & 3.70 & 1.63 & 1.52 & 2.07 & 5.79 & B20 \\
\hline 4.47 & 0.66 & 0.59 & 0.71 & 1.71 & 1.46 & 2.83 & 58.49 & 0.56 & 54 & 1.63 & 0.54 & 0.48 & 1.15 & 2.07 & B21 \\
\hline 2.98 & 0.90 & 0.35 & 1.33 & 1 & 1.02 & 3.09 & 1.06 & 0.32 & & 30 & .09 & 1 & 1.31 & 55 & B22 \\
\hline 3.97 & 2.17 & 8.30 & 0.90 & 25 & 0 & 5.06 & 1.08 & 0 & 1.81 & 2.89 & 0.18 & 2.35 & 3.43 & 1.15 & B23 \\
\hline 4.05 & 2.26 & 0.86 & 2.42 & 2.18 & 1.17 & 1.48 & 1.40 & 0.48 & 200 & .87 & 4.60 & 2.03 & 1.79 & .74 & B24 \\
\hline 2.92 & 2.34 & 3.22 & 2.92 & 58 & 2.63 & 4.68 & 3.22 & 1.46 & 4.09 & 4.97 & 2.63 & 0.88 & 1.46 & 7.02 & B25 \\
\hline 4.08 & 0 & 2.04 & 0 & & 0 & 0 & 0 & 0 & 0 & 0 & 0 & 0 & 4.08 & 0 & C1 \\
\hline 1.62 & 0.54 & 0 & .16 & & 0 & .16 & 0 & 0 & & & 0 & 87 & 40 & & $\mathrm{C} 2$ \\
\hline 5.92 & 1.97 & 1.97 & 5.26 & 39 & .32 & 3.95 & .32 & 1.32 & 2.63 & 1.97 & 0.66 & 1.97 & 7.24 & .24 & $\mathrm{C} 3$ \\
\hline 1.86 & 1.21 & 1.13 & 6.96 & 2.10 & 170 & 2.27 & 1.21 & 0.24 & 1.29 & 1.38 & 1.05 & 1.05 & 3.97 & 3.64 & C4 \\
\hline 1.67 & 1.37 & 0.74 & & & & 5. & 4 & 1.21 & 64 & .51 & 2.17 & 1.88 & .48 & 63 & $\mathrm{C5}$ \\
\hline 2 & 1.10 & 0.88 & 3.02 & 1.18 & & 0.17 & 0.4 & 0.02 & 14 & 3.75 & 0.34 & 0.56 & .13 & 18 & C6 \\
\hline 0.24 & 94 & & & & & & 2.35 & 0.24 & & 4 & 4.35 & 1.41 & 53 & & C7 \\
\hline 3.33 & 3.33 & 6.66 & & & 3.33 & & 0 & 0 & & 3.33 & 0 & 0 & 3.33 & & $\mathrm{C} 8$ \\
\hline 7.07 & 2.02 & 4.04 & 3.03 & 4.04 & 1.01 & 5.05 & 1.01 & 0 & 2.02 & 3.03 & 1.01 & 1.01 & 1.01 & .08 & $\mathrm{C} 9$ \\
\hline 2.19 & 1.18 & 1.22 & & & & 2.31 & .89 & 0.55 & & .56 & 0.55 & 62 & .25 & 55 & C10 \\
\hline 0.84 & 0.68 & 0.79 & 2.23 & 4.58 & & 2.29 & 1.40 & 0.66 & 1.02 & 1.72 & 0.41 & 5.56 & .07 & .02 & C11 \\
\hline 1.72 & 0.77 & 0.5 & 2.57 & 4. & & 1.39 & & 0.56 & 0.94 & 1.16 & & 2.16 & 3.65 & 56 & $\mathrm{C} 12$ \\
\hline 1.91 & & & & & & & & 0.78 & & & & 76 & .38 & & $\mathrm{C} 13$ \\
\hline 1.31 & 1.25 & & 3.85 & & & & & 0.93 & & 1.78 & 0.44 & 2.65 & 1.89 & 94 & C14 \\
\hline 4.14 & 2.41 & 2.87 & 3.2 & & & 3.91 & 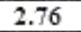 & 2.41 & & 2.19 & 30 & .37 & .10 & 45 & D1 \\
\hline 1.89 & 0.84 & 1.14 & 1.26 & 2.69 & 1.14 & 4.09 & 0.96 & 0.36 & 1.78 & 2 & 0.60 & 1.64 & .22 & .83 & D2 \\
\hline 1.53 & 1.51 & 1.54 & 1.63 & 4.53 & 1.37 & 3.33 & 1.66 & 0.57 & 1.79 & 2.27 & 1.21 & 1.72 & .30 & 56 & D3 \\
\hline 2.45 & 2.01 & 2.86 & 2.01 & 6.2 & & 4.6 & 1.51 & 2.42 & 3. & 3.29 & 1.24 & 0.97 & 2.69 & 5 & D4 \\
\hline 1.79 & 2 & 1.69 & 1.5 & & & & & 0.53 & & & 1.75 & 1.58 & .44 & & D5 \\
\hline 1.79 & 2.06 & & 1.7 & & & 3.5 & & 0.84 & 2.7 & 3.54 & 1.87 & 1.84 & .53 & .36 & D6 \\
\hline 16.29 & 0.85 & 1.54 & 0.22 & 2.32 & 0.1 & 0.82 & 2.09 & 0.20 & 0.13 & 4.47 & 0.12 & 0.69 & 0.16 & .56 & D7 \\
\hline 1.74 & 1.82 & 1.07 & 1.83 & 3.67 & 1.48 & 2.50 & 1.37 & 0.50 & 1.45 & 2.60 & 1.26 & 1.88 & .55 & 5.57 & D8 \\
\hline 4.17 & 1.04 & 5.21 & 1.04 & 3.1 & & 2.08 & 3.13 & 3.13 & 4.17 & 3.13 & 4.17 & 1.04 & 1.04 & 9.37 & 18 \\
\hline 1.96 & 2.23 & 2.23 & 2.70 & & 3.97 & 3.76 & 2.20 & 3.24 & 4.1 & 5.36 & 4.03 & 0.48 & .41 & .17 & D10 \\
\hline 3.57 & 3.57 & 3.57 & 3.57 & & & 1.79 & & 1.79 & 1.79 & 3.57 & 5.36 & 3.57 & 1.79 & 5.36 & D11 \\
\hline 3.06 & 1.96 & 2.42 & 2.68 & 3.61 & 2.11 & 3.1 & 3.20 & 1.22 & 2.23 & 3.08 & 1.76 & 2.01 & 3.01 & 4.84 & Average \\
\hline 2.38 & 0.96 & 2.27 & 1.40 & 1.47 & 1.91 & 1.53 & 7.81 & 1.10 & 1.22 & 1.35 & 1.37 & 1.41 & 5.26 & 2.26 & STDEV \\
\hline
\end{tabular}

Figure 3. Indicators of society and knowledge-based economy provinces of Iran in 2011 (percent) Source: Statistical Centre of Iran, 2011.

According to Figure 3, results of the analysis of the 31 provinces, with more than 75 million people in 2011 were as follows: 
- The first component (A) which includes indexesof "human capital" shows that:

-From among 75,150,000 people in the country, 27.34 percent $(20,547,000$ people) are employed (A1) as compared to Tehran which is $17.9 \%$ and Ilam which is $0.71 \%$.

-Although the rate of $13.45 \%$ is relatively low for higher education population (including graduate and student population) (A2) is relatively low, this ratio is almost doubled, i.e., 24\%, in Tehran. But in South Khorasan this value has the lowest value with $0.8 \%$.

-From among the $20,547,000$ country employees, $20.78 \%$ are highly educated (A3). This proportion is $24.36 \%$ for employees in Tehran and $0.89 \%$ for employees in Ilam.

-Among the 10,222,390 people with higher education, $7.66 \%$ are unemployed (A4); this value is the highest in Tehran with $19.97 \%$ and the lowest with $0.48 \%$ in South Khorasan.

-From among the 15,585,386 students of the country, 15.5\% are trainees of Technical and Vocational Training Organization (A5). The rate of this index is $21.86 \%$ in Isfahan and $0.58 \%$ in Hormozgan.

- The second component (B) which includes indexes of "economic structure" includes the following results Sub-indexes of "human resources" show that:

$-31.77 \%$ of the country's economically active population (B1) is engaged in the production of economic goods and services. Tehran with $16.76 \%$ and Ilam and Kohgiluyeh-Buyerahmad with $0.78 \%$ have the highest and the lowest economically active population, respectively.

-Economic participation rate, or the rate of activity (B2), which shows the ratio of working population to the working-age population, is $36.75 \%$ in Iran. It is the highest $(42.5 \%)$ in Ardabil and the lowest in Sistan-Baluchestan (26.1\%).

-Unemployment rate (B3), which represents the proportion of the working population to unemployed people in the country, is $12.22 \%$. It is the lowest in Yazd (6\%) and the highest in Alborz (19.3\%).

-Method of population distribution in three sectors of agriculture, industry and services (B4, B5, B6) reflect the stage of development or degeneration of society and economic and social development of it. In Iran, the share of employment in the agricultural sector is $21 \%$ (37.2\% in North Khorasan, $1.4 \%$ in Tehran), $32.36 \%$ in industrial sector (43.2\% in Yazd, 7.4\% in Ardabil) and 44.15\% in the services sector (62.7\% in Tehran, $6.3 \%$ in Ardebil).

-Among the 922,949 employment positions created institutional (B7) in the country, the highest rate goes to Tehran with $11.58 \%$ and the lowest rate is dedicated to Kohgiloyeh-Buyerahmad with 0.74 .

- In 2011, 523,198 jobs were created in Iran (B8) out of which $22.14 \%$ were created in Tehran and $0.10 \%$ were created in North Khorasan.

Sub-indexes of "industry and mining" show rate of benefit of the provinces in this regard. The following are provinces that have the highest and the lowest rates from this sub-indexes:

- From the 187 industrial clusters (B9) $13.37 \%$ were located in Isfahan, and it was $0.54 \%$ in each of the provinces of Ilam, Bushehr, Chahar Mahal Bakhtiari, South Khorasan, Kermanshah and Lorestan; from 14,498 industrial workshop (B10) 15.68\% were in Tehran and in $0.20 \%$ were in Ilam; from 12776 industrial cooperatives (B11) $11.68 \%$ were located in Tehran and $0.41 \%$ were placed in Alborz; from the total employment in industrial units (B12) at a rate of about 140314, 10.95\% were dedicated to Tehran and $0.35 \%$ in Kohgiloyeh-Buyerahmad; from a total of 1,282,992 workers of industrial workshops (B13) $21.46 \%$ were in Tehran and $0.16 \%$ in Ilam; from 4298 operating mines (B14) $5.10 \%$ were in Isfahan and $0.70 \%$ were in Alborzand from 1161 mineral cooperatives (B15) 22.05\% were working in Tehran and $0.17 \%$ in provinces of Ilam and Alborz.

Sub-indexes of "transport and communication" indicate that:

- From among a total of 110400 kilometers of roads under the controlling zone of ministry of roads and urbanization (B16), Hormozgan was responsible for $10.51 \%$ and Qom for $0.59 \%$ of it. From the 263,986 city public transportation vehicles (B17) $9.21 \%$ were in Isfahan and $0.28 \%$ were in Ardabil. From the 2638 Transportation cooperatives (B18) 10.99\% was in Hormozgan and $0.34 \%$ was in Qom. From 3970 postal units (B19) $8.44 \%$ were in Tehran and $0.76 \%$ were in Ilam, which are respectively the highest and the lowest indexes in the provinces.

Sub-indexes of "financial markets" show that: 
In a total of 18,315 banking units (B20) $18.71 \%$ were in Tehran and $0.72 \%$ were in Kohgiloyeh-Buyerahmad; in a total of $14,374,718$ of the paid facilities by banks to non-government parts in the economy critical parts (B21) $16.50 \%$ were in Tehran and Alborz had no loan payment. In a total of 28,963,664 cases of insurance issued (B22) $38.69 \%$ were in Tehran and $0.32 \%$ were in Kohgiloyeh-Buyerahmad. From a total of 554 Stock Exchange Member Brokerage Firms (B23) 18.05\% were in Tehran and in Alborz, Kohgiloyeh-Buyerahmad and Lorestan lacked any company. Of a total of 1283 credit cooperatives (B24) $25.88 \%$ was dedicated to Tehran and Qom lacked any company. From a total of 342 equity shares cooperative (B25) $7.02 \%$ were located in Fars and $0.88 \%$ in Qom and Alborz Persian which are respectively the highest and the lowest indexes in the provinces.

- The third component (C) which includes indexes of "innovation systems" shows that:

A total of 49 certificates and licenses of research centers (C1) 46.94\% are in Tehran and in provinces of Ardebil, Alborz, Ilam, Bushehr, Chahar Mahal Bakhtiari, South Khorasan, North Khorasan, Khuzestan, Sistan-Baluchestan, Fars, Qom, Tehran, Kerman , Kermanshah, Kohgiloyeh-Buyerahmad, Golestan, Gilan, Lorestan, Markazi and Hamedan no center are seen. From a total of 185 certificates and licenses research and development (C2) 13.52\% are in Khorasan Razavi and provinces of West Azarbaijan, Alborz, South Khorasan, Khuzestan, Sistan-Baluchistan, Kurdistan, Kohgiloyeh-Buyerahmad, Golestan, Lorestan and Hormozgan are lacking a certificate. From among a total of 152 projects national development fund (C3) $8.55 \%$ are in Khorasan Razavi and Sistan-Baluchestan lacks any. Out of a total of 1,236 units certified quality management system (C4) $31.15 \%$ are in Tehran and $0.24 \%$ Kohgiloyeh-Buyerahmad. Among a total of 8249 goods export companies (C5) $36.37 \%$ are in Tehran and in $0.18 \%$ are in ChaharMahal Bakhtiyari. Also out of a total of 37,193 billion rials non-oil exports (C6) $22.73 \%$ is dedicated to Bushehr and Kohgiloyeh-Buyerahmad is responsible for only $0.02 \%$. From a total of 850 cases of domestic and international exhibitions (C7) $11.76 \%$ are in Farsand $0.24 \%$ in each of the provinces of Alborz, Ilam, Khorasan Razavi, Semnan, Kermanshah, Kohgiloyeh-Buyerahmad, Mazandaran and Yazd. From 30 Science and technology parks and towns (C8) 10\% are located in Tehran and in Ardebil, Ilam, ChaharMahal-Bakhtiyari, Sistan-Baluchestan, Qom, kurdestan, Golestan and Kohgiloyeh-Buyerahmad are lacking. From a total of 99 growth centers of innovation units (C9) $21.21 \%$ are in Tehran and Kohgiloyeh-Buyerahmad lacks these centers. A total of 2,376 workshop R \& D activities (C10) $23.49 \%$ are in Tehran $0.29 \%$ in Ilam. Out of a total of 17473 researcher workshops of R \& D (C11) in Tehran there exists $38.56 \%$ and in North Khorasan $0.20 \%$. Further, in a total of 6913 R \& D activities workshop technicians (C12) $43.14 \%$ are in Tehran and Ilam is lacking this technicians. In addition, from a total of 64642 research project of $\mathrm{R} \& \mathrm{D}$ activity workshops (C13) $33.10 \%$ are in Tehran and $0.22 \%$ in Ilam. Finally, from a total of $14,556,376$ million rials cost of research and development in R \& D activity workshops (C14) $41.22 \%$ are in Tehran and $0.10 \%$ in Ilam which are respectively the highest and lowest indexes.

- The fourth component (D) as indexes of "information and communication technology", which may indicate that:

Internet penetration (D1) is 55 in Alborz (6.32\%) and 12 in Sistan-Baluchestan (1.38 percent), Internet subscribers (D2) is $36.69 \%$ in Tehran and $0.36 \%$ in Chaharmahal and Kohgiloyeh-Buyerahmad, Internet users (D3) is $31.41 \%$ in Tehran and $0.49 \%$ in Ilam, Internet service workshops (D4) is $10.34 \%$ in Tehranand $0.61 \%$ in Ilam, fixed telephone subscribers (D5) is $23.15 \%$ in Tehran and $0.53 \%$ in Kohgiloyeh-Buyerahmad, mobile subscribers (D6) is $22.27 \%$ in Tehran and $0.69 \%$ in North Khorasan, microwave transmission communication channels (D7) is $24.11 \%$ in Khuzestan and $0.005 \%$ in Ilam, urban households having a computer (D8) are $30.66 \%$ in Tehran and $0.46 \%$ in Ilam, radio stations (D9) are 9.37\% in Fars and Alborz is free of any station, television stations and analog (D10) is $7.3 \%$ in Sistan-Baluchestan province and Alborz has no station, digital television stations (D11) is 7.14\% in Tehran and Alborz has no station and these values are respectively the highest and the lowest indexes of provinces.

\subsection{Investigation of the Way of Distribution and of Indexes in the Provinces through Inferential Analysis}

Spearman correlation coefficient was used to investigate the distribution and frequency of society and knowledge-based economy in the provinces of Iran and determine the appropriateness and desirability rank correlation and the population of each province with the highest composite indexes society and knowledge-based economy of the. For this purpose, with the help of standard varieties (Z-score) benefit combine index has been calculated for every province and then using the Spearman rank correlation composite index of fitness and knowledge-based society and economy were compared with population ranks of the provinces. 
Table 4. Correlation coefficient between population rank and benefit rank of the knowledge-based society and economy indexes in Iranian provinces

\begin{tabular}{lllcc}
\hline & & Population & Indexes \\
\hline Spearman's rho & Population & Correlation Coefficient & 1.000 & $.836^{* *}$ \\
& & Sig.(2-tailed) & & .000 \\
& & $\mathrm{~N}$ & 31 & 31 \\
& \multirow{2}{*}{ Indexes } & Correlation Coefficient & $.836^{* *}$ & 1.000 \\
& & Sig.(2-tailed) & .000 & \\
& & $\mathrm{~N}$ & 31 & 31 \\
\hline
\end{tabular}

**. Correlation is significant at the 0.01 level (2-tailed).

The results obtained from are numbers between 0 and 1 . The results obtained are closer to 1 , the optimal distribution and knowledge-based society and economy rank indexes would be proportionate to the population rank of each province. On the contrary, the closer the number to 0 , the more disproportionate and inappropriate the distribution of indexes.

The results of this comparison indicated high proportion and correlation (0.836) between the population needs and having indexes of society and knowledge-based economy and as a result a relatively proportional and fair distribution of the indexes in the provinces of the country. But in the meantime, the difference between the population rank and having indexes is higher for Sistan-Baluchestan, Markazi, Ardebil, Qazvin, Yazd, Semnan, Bushehr.

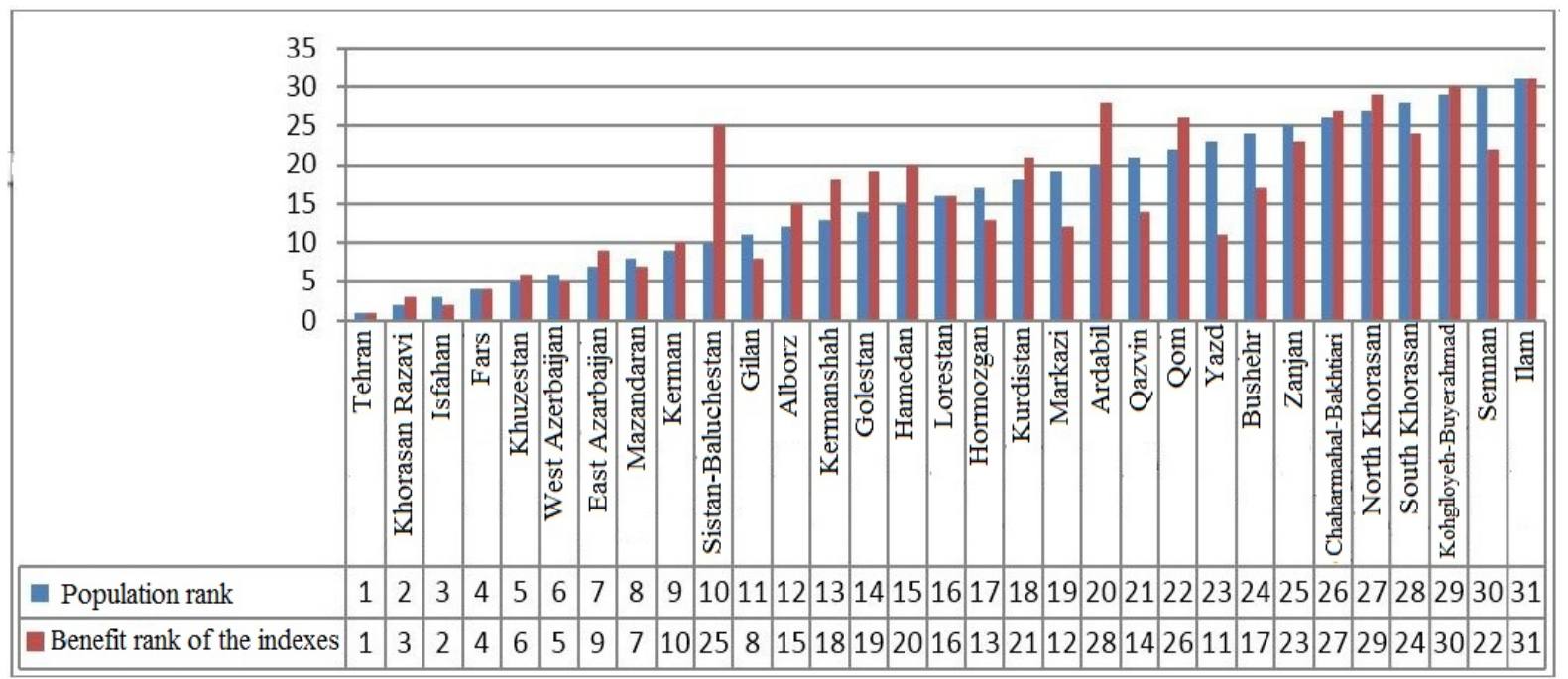

Figure 4. Comparison of population rank and benefit rank of the knowledge-based society and economy indexes in Iranian provinces

\subsection{Determining the Degree of the Relative Importance of the Indexes Using the Shannon Entropy Method}

To determine the degree of relative importance of research indexes by using the Shannon Entropy method showed that the index of "urban households have computers" has the highest degree of relative importance $(0.02005)$ and "science and technology parks and towns" has the lowest degree of relative importance (0.01357). Also, the indexes "employees with highly education", "Internet users" and "fixed telephone subscribers", after the indexes of "urban households having a computer", as well as indexes of "digital TV stations", "domestic and international exhibitions" and "microwave transmission communication channels" after the index "towns and science and technology parks" had the highest and the lowest degrees of relative importance (Table 5). 
Remarkably, the components of the "economic structure", "innovation systems", "ICT" and "human capital" are the highest and the lowest in their relative importance so that regarding components of the economic structure, "insurance issued" and "mining cooperatives" are respectively the highest and the lowest, concerning the components of innovation system, "workshop technicians in R \& D activities" and "science and technology parks and towns" are respectively the highest and the lowest, regarding ICT components "urban households having a computer" and "digital TV stations" are respectively the highest and the lowest, and regarding components of human capital, "employees with higher education" and "trainees of technical and vocational training organization" have respectively the highest and the lowest level of relative importance.

Table 5. Degree of superiority characteristics of the knowledge-based society and economy

\begin{tabular}{|c|c|c|}
\hline & Index & Weight \\
\hline D8 & Urban households having a computer & 0.02005 \\
\hline $\mathrm{A} 3$ & Employees with higher education & 0.02001 \\
\hline D3 & Internet users & 0.02001 \\
\hline D5 & Fixed telephone subscribers & 0.02001 \\
\hline $\mathrm{C} 13$ & Workshops research projects R \& D activities & 0.01999 \\
\hline $\mathrm{C} 10$ & Workshops R \& D activities & 0.01993 \\
\hline A2 & Population with higher education & 0.01992 \\
\hline $\mathrm{C} 14$ & $R \& D$ costs $R \& D$ activity workshops & 0.01986 \\
\hline D2 & Internet Subscribers & 0.01986 \\
\hline D6 & Mobile Subscribers & 0.01986 \\
\hline $\mathrm{C} 11$ & Researchers workshops R \& D activities & 0.01983 \\
\hline B22 & Insurance issued letters & 0.01981 \\
\hline $\mathrm{C} 12$ & Workshop technicians in R \& D activities & 0.01981 \\
\hline B20 & Banking units & 0.01979 \\
\hline A1 & Working population & 0.01975 \\
\hline $\mathrm{B} 1$ & Economically active population & 0.01973 \\
\hline A4 & Highly educated unemployed & 0.01958 \\
\hline B13 & Industrial shop workers & 0.01937 \\
\hline $\mathrm{C} 4$ & Units certified quality management system & 0.01937 \\
\hline $\mathrm{C} 5$ & Companies exporting goods & 0.01936 \\
\hline $\mathrm{C} 1$ & Certificates and licenses research centers & 0.01925 \\
\hline B10 & Industrial workshop & 0.01915 \\
\hline B25 & Justice stock cooperatives & 0.01903 \\
\hline A5 & Technical and Vocational Education Training Organization victims & 0.01893 \\
\hline B17 & Urban public transport & 0.01889 \\
\hline D1 & Internet penetration & 0.01889 \\
\hline B24 & Credit cooperatives & 0.01879 \\
\hline D4 & Internet service workshops & 0.01873 \\
\hline B12 & Employment rate in industrial units & 0.01845 \\
\hline B8 & Careers & 0.01844 \\
\hline D10 & Analog TV stations & 0.01843 \\
\hline B5 & The share of employment in industry & 0.01816 \\
\hline B11 & Industrial cooperative companies & 0.01782 \\
\hline
\end{tabular}




\begin{tabular}{clc}
\hline B2 & Economic Participation Rate & 0.01779 \\
C9 & Incubators of technology & 0.0177 \\
B18 & Transport cooperatives & 0.01767 \\
B6 & The share of employment in the service sector & 0.01766 \\
B23 & Stock Exchange member brokerage firms & 0.01759 \\
B7 & Employment of the device & 0.01757 \\
B9 & Industrial clusters & 0.01748 \\
B21 & Loans to non-bank payment in important economic sectors & 0.01742 \\
B14 & Mine operating & 0.01704 \\
B4 & The share of employment in agriculture & 0.01659 \\
B3 & Unemployment & 0.01651 \\
B16 & Roads under the jurisdiction of the Ministry of Roads and Urban Development & 0.01638 \\
C3 & The National Development Fund & 0.01619 \\
D9 & Radio stations & 0.01606 \\
B19 & Postal units & 0.01595 \\
C2 & Certification and Licensing Research \& Development & 0.0158 \\
C6 & Non-oil exports & 0.01574 \\
B15 & Mining cooperatives & 0.01568 \\
D7 & Microwave transmission communication channels & 0.01527 \\
C7 & Domestic and international exhibitions & 0.01489 \\
D11 & Digital TV stations & 0.01455 \\
C8 & Towns and parks of science and technology & 0.01357 \\
\hline
\end{tabular}

Source: authors, 2015.

\subsection{Evaluation of the Provinces in the Knowledge-Based Society and Economy with Multi-Attribute Decision Making Methods}

Using the TOPSIS method, the benefit rates of provinces of Iran from the knowledge-based society and economy were calculated and rank of each province was obtained in various indexes. According to calculations, Tehran province as highest benefit province is ranked 1on all four indexes of "human capital", "economic structure", "innovation" and "ICT systems", with values $0.941,0.741,0.8206$ and 0.752 , respectively. In contrast, South Khorasan in "human capital" index with value 0.009 , Ilam in economic structure index with value 0.140 , Kohgiloyeh-Buyerahmad in innovation systems index with value 0.024 , and North Khorasan in information and communication technology index with value 0.062 were identified as the lowest benefited provinces (Table 6).

Table 6. The rate and rank the Iranian provinces of indices society and knowledge-based economy with the TOPSIS

\begin{tabular}{ccccccccc}
\hline Province & Human capital & $\begin{array}{c}\text { Economic } \\
\text { structure }\end{array}$ & $\begin{array}{c}\text { Innovation } \\
\text { systems }\end{array}$ & $\begin{array}{c}\text { Information and } \\
\text { communication } \\
\text { technology }\end{array}$ \\
\cline { 2 - 10 } & Value & Rank & Value & Rank & Value & Rank & Value & Rank \\
\hline East Azarbaijan & 0.1989 & 7 & 0.3022 & 9 & 0.1329 & 6 & 0.2341 & 6 \\
West Azerbaijan & 0.1246 & 11 & 0.2881 & 11 & 0.0657 & 19 & 0.1680 & 10 \\
Ardabil & 0.0527 & 17 & 0.1417 & 30 & 0.0661 & 18 & 0.0965 & 22 \\
Isfahan & 0.3146 & 2 & 0.4818 & 2 & 0.3154 & 2 & 0.2690 & 5 \\
\hline
\end{tabular}




\begin{tabular}{ccccccccc}
\hline Alborz & 0.14424 & 10 & 0.2649 & 14 & 0.1102 & 11 & 0.1382 & 15 \\
Ilam & 0.0253 & 26 & 0.1394 & 31 & 0.0343 & 28 & 0.0621 & 29 \\
Bushehr & 0.0333 & 23 & 0.2310 & 17 & 0.1216 & 8 & 0.0983 & 21 \\
Tehran & 0.9412 & 1 & 0.7405 & 1 & 0.8206 & 1 & 0.7516 & 1 \\
Chaharmahal-Bakhtiari & 0.0216 & 27 & 0.1702 & 27 & 0.0634 & 20 & 0.0708 & 28 \\
South Khorasan & 0.0085 & 31 & 0.1916 & 23 & 0.0384 & 27 & 0.2215 & 7 \\
Khorasan Razavi & 0.2961 & 3 & 0.4491 & 3 & 0.2158 & 4 & 0.2788 & 4 \\
North Khorasan & 0.0166 & 29 & 0.1438 & 29 & 0.0339 & 29 & 0.0615 & 31 \\
Khuzestan & 0.2150 & 5 & 0.3034 & 8 & 0.1050 & 12 & 0.3075 & 2 \\
Zanjan & 0.0302 & 25 & 0.1780 & 26 & 0.0588 & 22 & 0.0618 & 30 \\
Semnan & 0.0124 & 30 & 0.1843 & 25 & 0.0977 & 14 & 0.1111 & 20 \\
Sistan-Baluchestan & 0.0423 & 21 & 0.2209 & 19 & 0.0422 & 24 & 0.1648 & 11 \\
Fars & 0.2830 & 4 & 0.3818 & 5 & 0.1552 & 5 & 0.2801 & 3 \\
Qazvin & 0.0365 & 22 & 0.2175 & 20 & 0.2373 & 3 & 0.0805 & 27 \\
Qom & 0.0315 & 24 & 0.1985 & 21 & 0.0879 & 15 & 0.0829 & 25 \\
Kurdistan & 0.0463 & 19 & 0.1907 & 24 & 0.0279 & 30 & 0.1246 & 17 \\
Kerman & 0.1452 & 9 & 0.2874 & 12 & 0.0675 & 17 & 0.1606 & 12 \\
Kermanshah & 0.0933 & 12 & 0.2238 & 18 & 0.0627 & 21 & 0.1333 & 16 \\
Kohgiloyeh-Buyerahmad & 0.0205 & 28 & 0.1562 & 28 & 0.0235 & 31 & 0.0924 & 23 \\
Golestan & 0.0639 & 15 & 0.4101 & 4 & 0.0340 & 25 & 0.1569 & 13 \\
Gilan & 0.1491 & 8 & 0.2971 & 10 & 0.1033 & 13 & 0.1543 & 14 \\
Lorestan & 0.0834 & 13 & 0.2479 & 15 & 0.0386 & 26 & 0.1170 & 19 \\
Mazandaran & 0.2131 & 6 & 0.3099 & 7 & 0.1149 & 10 & 0.1953 & 9 \\
Markazi & 0.0565 & 16 & 0.2369 & 16 & 0.1255 & 7 & 0.0913 & 24 \\
Hormozgan & 0.0430 & 20 & 0.3109 & 6 & 0.0711 & 16 & 0.1215 & 18 \\
Hamedan & 0.0652 & 14 & 0.1936 & 22 & 0.0494 & 23 & 0.0827 & 26 \\
Yazd & 0.0463 & 18 & 0.2817 & 13 & 0.1191 & 9 & 0.1997 & 8 \\
\hline
\end{tabular}

Source: authors, 2015.

In order to evaluate the positions of provinces in the society and knowledge-based economy use was made of two methods of TOPSIS and VIKOR. The results showed that TOPSIS method revealed that Tehran, Isfahan and Khorasan had the first, the second and the third ranks with values (coefficient priority) $0.740,0.367$ and 0.295 , respectively, and Kohgiloyeh-Buyerahmad province, northern Khorasan and Ilam got the last three ranks with values $0.081,0.078$ and 0.069 , respectively.

Results of VIKOR method also indicated that Isfahan, Tehran and East Azerbaijan with values 1.129, 1.067 and 0.869 respectively ranked the first to the third, and South Khorasan, Kohgiloyeh-Buyerahmad and Ilam provinces with value $0.636,0.632$ and 0.627 were last in the rankings.

As can be seen, in VIKOR method the position of Tehranwhich was the first in TOPSIS method dropped to the second here. Conversely, Isfahan province which was the second in TOPSIS method promoted to the first rank. Also in this method Ilam province did not change in its ranking. Also, positions of provinces had significant changes, some provinces have promotions while others have gotten drops (Table 7). 
Table 7. Place of Iran's provinces in society and knowledge-based economy with multi attribute decision making methods

\begin{tabular}{|c|c|c|c|c|c|}
\hline \multicolumn{3}{|l|}{ TOPSIS } & \multicolumn{3}{|l|}{ VIKOR } \\
\hline Province & Value & Rank & Province & Value & Rank \\
\hline Tehran & 0.7398 & 1 & Isfahan & 1.1293 & 1 \\
\hline Isfahan & 0.3671 & 2 & Tehran & 1.0664 & 2 \\
\hline Khorasan Razavi & 0.2947 & 3 & East Azarbaijan & 0.8686 & 3 \\
\hline Fars & 0.2611 & 4 & Khorasan Razavi & 0.86537 & 4 \\
\hline East Azarbaijan & 0.2362 & 5 & Fars & 0.7603 & 5 \\
\hline Khuzestan & 0.2141 & 6 & Khuzestan & 0.7603 & 5 \\
\hline Golestan & 0.1983 & 7 & Gilan & 0.7603 & 5 \\
\hline Mazandaran & 0.1926 & 8 & Kerman & 0.7558 & 6 \\
\hline Qazvin & 0.1805 & 9 & Markazi & 0.7407 & 7 \\
\hline Gilan & 0.1703 & 10 & Mazandaran & 0.7255 & 8 \\
\hline Yazd & 0.1630 & 11 & Yazd & 0.7174 & 9 \\
\hline Kerman & 0.1617 & 12 & Qazvin & 0.7161 & 10 \\
\hline Hormozgan & 0.1610 & 13 & Golestan & 0.7134 & 11 \\
\hline West Azerbaijan & 0.1609 & 14 & Qom & 0.7090 & 12 \\
\hline Alborz & 0.1540 & 15 & Kermanshah & 0.7066 & 13 \\
\hline Bushehr & 0.1514 & 16 & Hamedan & 0.7024 & 14 \\
\hline Markazi & 0.1414 & 17 & Bushehr & 0.6999 & 15 \\
\hline Sistan-Baluchestan & 0.1311 & 18 & Lorestan & 0.6949 & 16 \\
\hline South Khorasan & 0.1302 & 19 & Alborz & 0.6948 & 17 \\
\hline Lorestan & 0.1288 & 20 & Zanjan & 0.6879 & 18 \\
\hline Kermanshah & 0.1255 & 21 & West Azerbaijan & 0.6847 & 19 \\
\hline Semnan & 0.1142 & 22 & Ardabil & 0.6837 & 20 \\
\hline Kurdistan & 0.1083 & 23 & Kurdistan & 0.6747 & 21 \\
\hline Qom & 0.1075 & 24 & Hormozgan & 0.6696 & 22 \\
\hline Zanjan & 0.1055 & 25 & Sistan-Baluchestan & 0.6678 & 23 \\
\hline Hamedan & 0.1022 & 26 & Semnan & 0.6607 & 24 \\
\hline Ardabil & 0.0967 & 27 & Chaharmahal-Bakhtiari & 0.6558 & 25 \\
\hline Chaharmahal-Bakhtiari & 0.0906 & 28 & North Khorasan & 0.6423 & 26 \\
\hline Kohgiloyeh-Buyerahmad & 0.0813 & 29 & South Khorasan & 0.6359 & 27 \\
\hline North Khorasan & 0.0781 & 30 & Kohgiloyeh-Buyerahmad & 0.6315 & 28 \\
\hline Ilam & 0.0692 & 31 & Ilam & 0.6271 & 29 \\
\hline
\end{tabular}

Source: authors, 2015.

In order to better explain the differences in methodology, the most important index in the center of the distribution and trends (including amplitude and mean and Standard Deviation) scores were obtained from the methods TOPSIS and VIKOR (Table 8).

Comparison of changes in ranks of the provinces shows that some had the highest while others had the lowest changes. Indexes such as standard deviation and ranges can easily reflect these differences. Accordingly, the highest changes have been seen for provinces of Qom, Hamadan, Arak, Kermanshah, which is respectively 12, 12 and 10. The highest standard deviations are also related to the above-mentioned provinces. Mazandaran 
showed no change in ranking. In addition, provinces of Tehran, Isfahan, Fars, Khuzestan, Qazvin, Bushehr and Kohgiloyeh-Buyerahmad also had the least change in this analysis. Standard deviation for these provinces was the lowest compared to other provinces (Figures 5 and 6).

Table 8. Rank and statistics of trend and distribution to center of MADM models

\begin{tabular}{|c|c|c|c|c|c|c|c|}
\hline \multirow{2}{*}{ Province } & \multicolumn{2}{|c|}{ Ranks } & \multicolumn{5}{|c|}{ Indicators of distribution and trends center } \\
\hline & TOPSIS & VIKOR & Max & Min & Range & Average & SD \\
\hline Tehran & 1 & 2 & 2 & 1 & 1 & 1.5 & 0.707107 \\
\hline Isfahan & 2 & 1 & 2 & 1 & 1 & 1.5 & 0.707107 \\
\hline Khorasan Razavi & 3 & 4 & 4 & 2 & 2 & 3.5 & 1.414214 \\
\hline Fars & 4 & 5 & 5 & 4 & 1 & 4.5 & 0.707107 \\
\hline East Azarbaijan & 5 & 3 & 5 & 3 & 2 & 4 & 1.414214 \\
\hline Khuzestan & 6 & 5 & 6 & 5 & 1 & 5.5 & 0.707107 \\
\hline Golestan & 7 & 11 & 11 & 7 & 4 & 9 & 2.828427 \\
\hline Mazandaran & 8 & 8 & 8 & 8 & 0 & 8 & 0 \\
\hline Qazvin & 9 & 10 & 10 & 9 & 1 & 9.5 & 0.707107 \\
\hline Gilan & 10 & 5 & 10 & 5 & 5 & 7.5 & 3.535534 \\
\hline Yazd & 11 & 9 & 11 & 9 & 2 & 10 & 1.414214 \\
\hline Kerman & 12 & 6 & 12 & 6 & 6 & 9 & 4.242641 \\
\hline Hormozgan & 13 & 22 & 22 & 13 & 9 & 17.5 & 6.363961 \\
\hline West Azerbaijan & 14 & 19 & 19 & 14 & 5 & 16.5 & 3.535534 \\
\hline Alborz & 15 & 17 & 17 & 15 & 2 & 16 & 1.414214 \\
\hline Bushehr & 16 & 15 & 16 & 15 & 1 & 15.5 & 0.707107 \\
\hline Markazi & 17 & 7 & 17 & 7 & 10 & 12 & 7.071068 \\
\hline Sistan-Baluchestan & 18 & 23 & 23 & 18 & 5 & 20.5 & 3.535534 \\
\hline South Khorasan & 19 & 27 & 27 & 19 & 8 & 23 & 5.656854 \\
\hline Lorestan & 20 & 16 & 20 & 16 & 4 & 18 & 2.828427 \\
\hline Kermanshah & 21 & 13 & 21 & 13 & 8 & 17 & 5.656854 \\
\hline Semnan & 22 & 24 & 24 & 22 & 2 & 23 & 1.414214 \\
\hline Kurdistan & 23 & 21 & 23 & 21 & 2 & 22 & 1.414214 \\
\hline Qom & 24 & 12 & 24 & 12 & 12 & 18 & 8.485281 \\
\hline Zanjan & 25 & 18 & 25 & 18 & 7 & 21.5 & 4.949747 \\
\hline Hamedan & 26 & 14 & 26 & 14 & 12 & 20 & 8.485281 \\
\hline Ardabil & 27 & 20 & 27 & 20 & 7 & 23.5 & 4.949747 \\
\hline Chaharmahal-Bakhtiari & 28 & 25 & 28 & 25 & 3 & 26.5 & 2.12132 \\
\hline Kohgiloyeh-Buyerahmad & 29 & 28 & 29 & 28 & 1 & 28.5 & 0.707107 \\
\hline North Khorasan & 30 & 26 & 30 & 26 & 4 & 28 & 2.828427 \\
\hline Ilam & 31 & 29 & 31 & 29 & 2 & 30 & 1.414214 \\
\hline
\end{tabular}

Source: authors, 2015. 


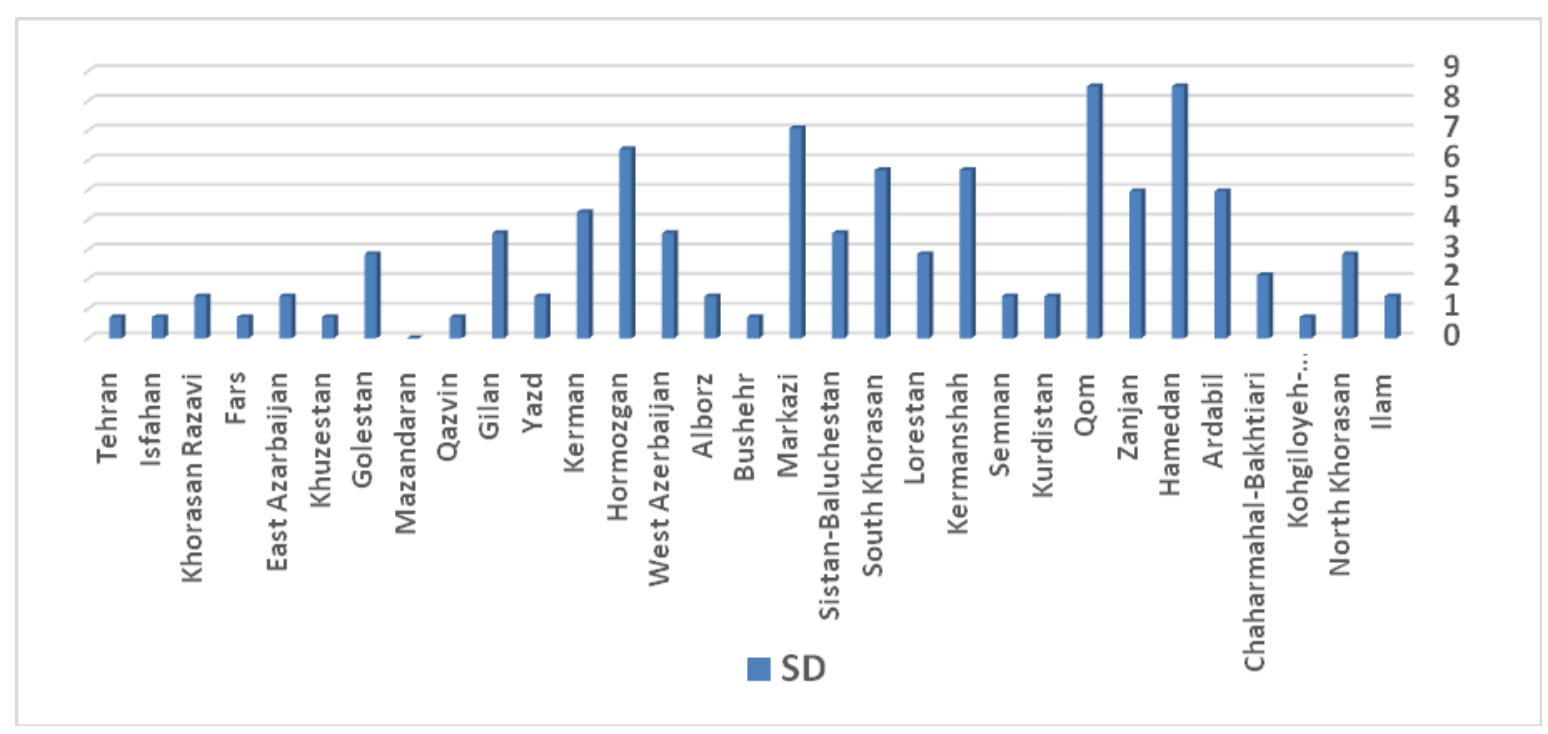

Figure 5. SD methods by province

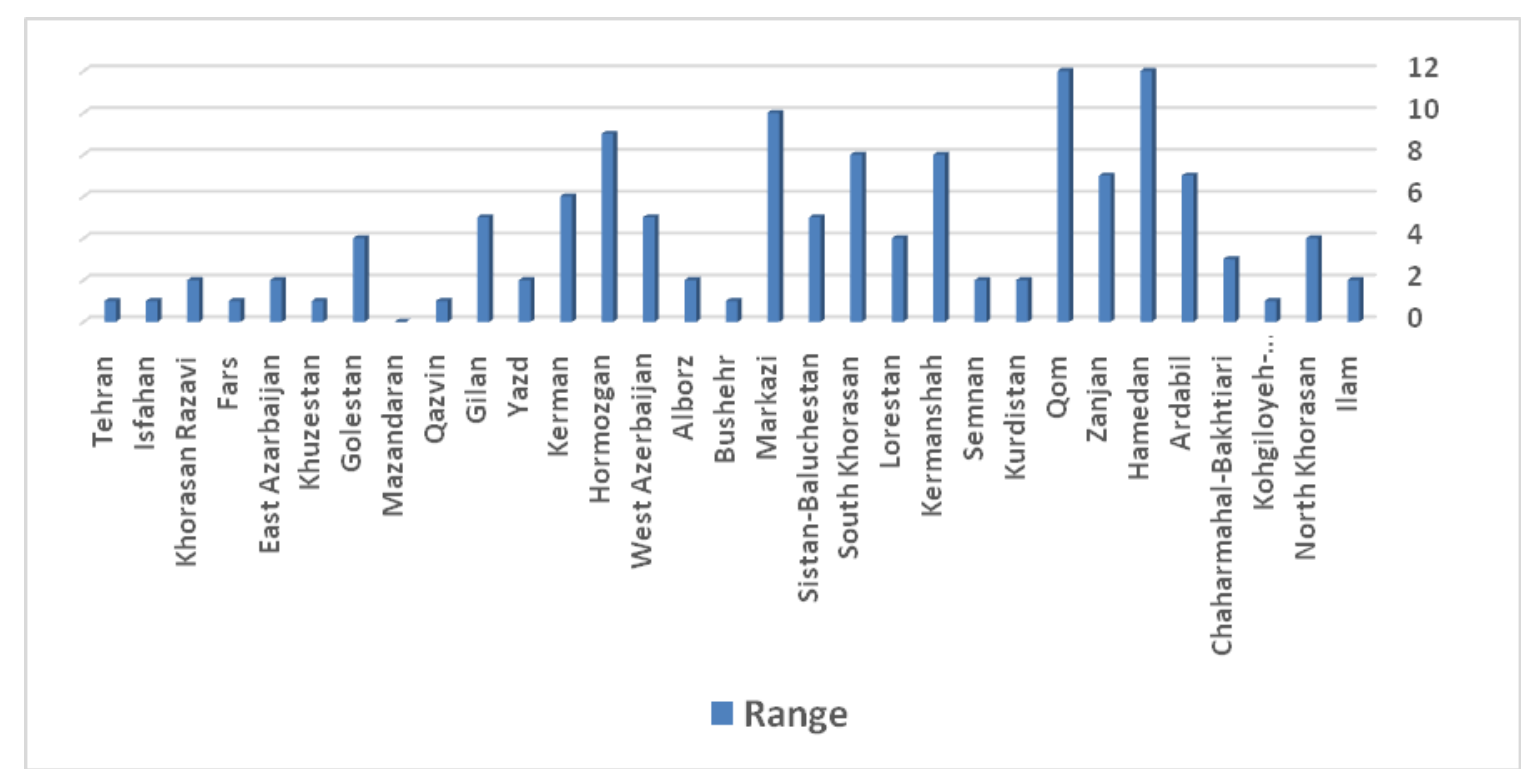

Figure 6. Changes in the methods by province

\subsection{Classification of Iranian Provinces through Cluster Analysis}

Using density-based hierarchical cluster analysis in the SPSS software, provinces were clustered into three levels on the basis of a knowledge-based society and economy indexes. As shown in Figure 7, with regard to the threshold of 6, 3 groups of homogeneous clusters of provinces (high, mid and low benefit) can be seen and analyzed. This reflects great differences between provinces depending on the extent of their participation in the knowledge-based society and economy.

First cluster: in this group only Tehran exists which has the highest level in terms of indexes of the knowledge-based society and economy.

Second cluster: in this group, East Azerbaijan, Isfahan, Khorasan Razavi, Khuzestan, Fars, which are at an intermediate level in terms of indexes of knowledge-based society and economy in the region.

Third cluster: in this group, other 25 provinces exist at the lowest level in terms of indexes of society and knowledge-based economy in the region. 
Table 9. Classification of provinces using cluster analysis

\begin{tabular}{ccc}
\hline cluster & Province & Rate of benefit \\
\hline 1 & Tehran & High benefit \\
2 & East Azarbaijan, Isfahan, Khorasan Razavi, Khuzestan, Fars & Mid benefit \\
& Gilan, Mazandaran, Kerman, Golestan, Qazvin, Yazd, Markazi, Bushehr, Alborz, & \\
3 & Western Azerbaijan, Kermanshah, Hormozgan, Lorestan, Qom Hamedan, & Low benefit \\
& Sistan-Baluchestan, Zanjan, Kurdistan, Semnan, South Khorasan, Ardabil, & \\
& Chaharmahal-Bakhtiari, North Khorasan, Kohgiloyeh-Buyerahmad, Ilam & \\
\hline
\end{tabular}

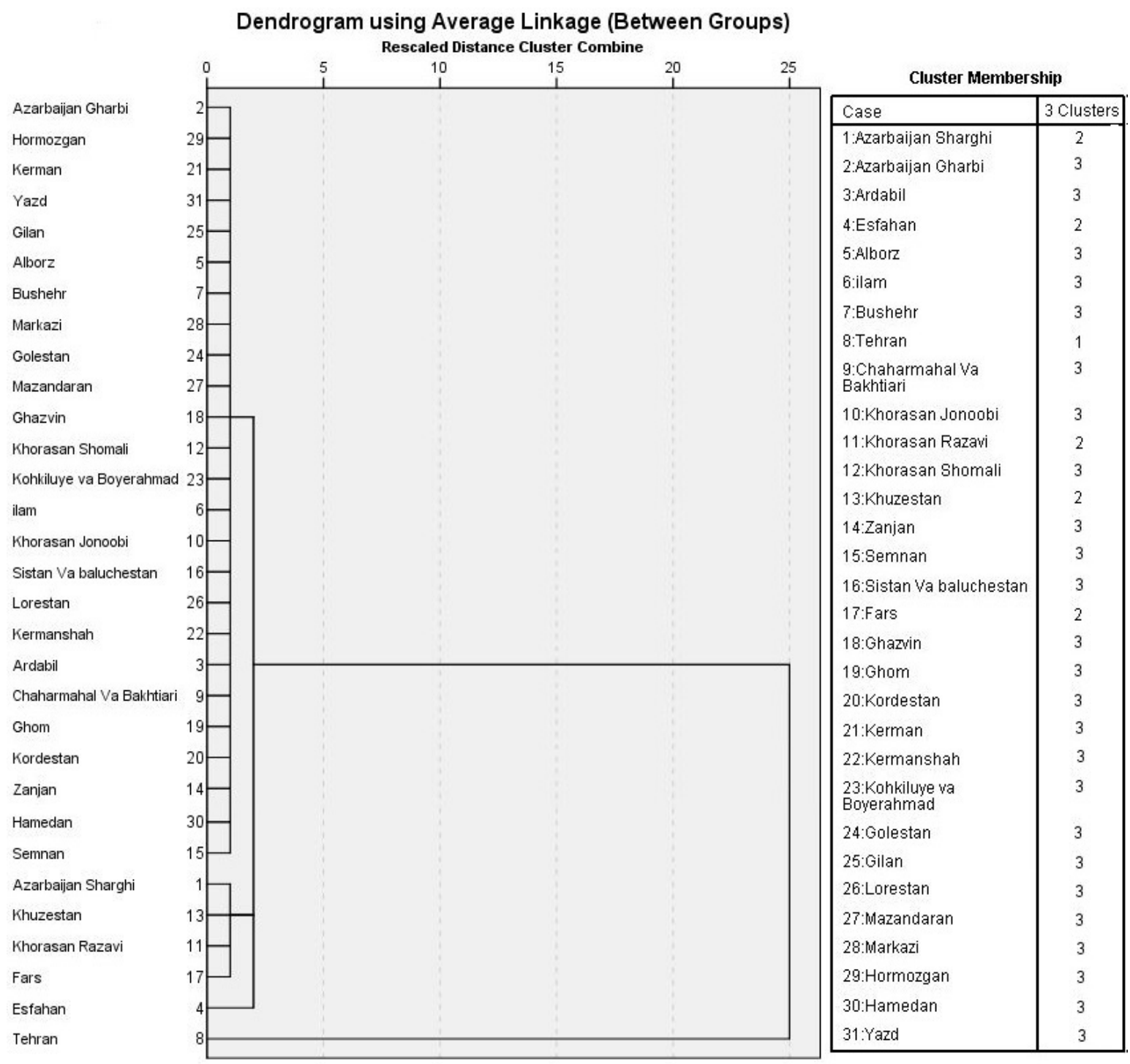

Figure 7. Clustering hierarchical cluster analysis dendrogram chart provinces with condensation on the indexes society and knowledge-based economy

Finally, for the spatial analysis, capabilities of provinces in knowledge-based society and economy is used using standard deviation and the degree of homogeneity of the classification of Geographic Information System (GIS) (Figure 8). This map shows that the paramount condition of provinces is critical in terms of having indexes of knowledge-based economy. In other words, a significant amount of Iranian provinces have not yet moved toward reaching knowledge-based society and economy. 


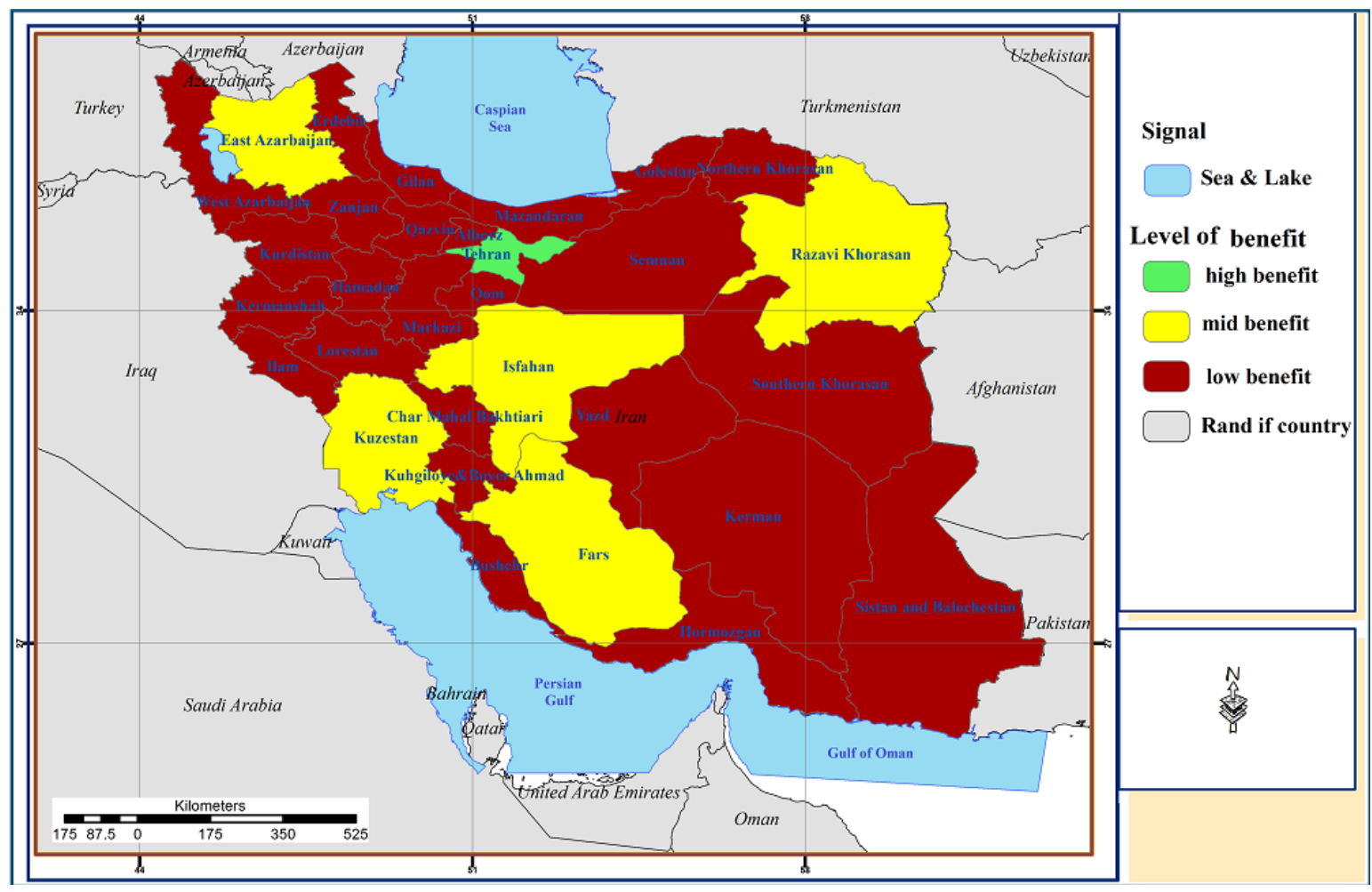

Figure 8. Viewing the spatial position of the provinces of Iran's society and knowledge-based economy

\section{Conclusion}

This study aimed to evaluate the parameters of knowledge-based society and economy in the 31 provinces of Iran and the spatial pattern of the index study was conducted to benefit the provinces. To this end, the 55 bit indexes divided into four basic components of "human capital", "economic structure", "innovation system" and "information and communication technology" to identify the values of each of the provinces for 2011 were collected. After gathering the necessary data, the descriptive analysis, distribution and knowledge-based economy in the region of indicators showed that the these measures are provinces that have more than 3 million people, are more likely (Tehran, Isfahan, Khorasan, Fars, East Azarbaijan and Khuzestan). The Tehran province of Ilam Average 16.62 and 1.05 respectively with highest average and the lowest of these parameters (Table 4).

In the inferential analysis, using the methods of transforming figures into standard values (z-scores) and Spearman correlation coefficient, the distribution state and the degree of correlation and relevance of "the rank of indicators of knowledge-based society and economy" comparing with "population rank of provinces" were investigated. The results of the results of the correlation coefficient test indicate high relevance and correlation (0.836) between population needs and the state of enjoyment of indicators of the knowledge-based society and economy and consequently, relatively appropriate and fair distribution of indicators within provinces of Iran. But, in this regard, there is differences between the population rank and the rank of enjoyment from indicators in Sistan-Baluchestan, Markazi, Ardebil, Qazvin, Yazd, Bushehr, and Semnan provinces. Therefore, regarding the expansion and development of these indicators in the mentioned provinces, more appropriate attention and planning should be conducted and the distribution of such indicators should be conducted appropriate with their population needs.

Using TOPSIS, the degree of enjoyment of provinces form indicators in the knowledge-based society and economy was calculated and the rank of each provinces in indicators were identified. Investigations indicate a high imbalance in the mode of distributing these indicators in provinces of Iran. Accordingly, Tehran Province is considered as the most enjoyed province and enjoys the first rank in terms of all four indicators of human capital, economic structure, innovation systems, and ICT with values as $0.941,0.741,0.821$, and 0.752 respectively, while South Khorasan Province in the indictor of human capital (0.009), Ilam Province in economic stricture indicator (0.140), Kohgiluyeh-Buyerahmad in the innovation system indicator (0.024), and North Khorasan Province in the ICT indicator $(0.062)$ are considered as the least enjoyed provinces. 
To evaluate the status of provinces in the knowledge-based society and economy, the two TOPSIS and VIKOR methods were used. The results of evaluating with TOPSIS indicate that Tehran, Isfahan, and Khorasan Razavi with values as $0.740,0.368$, and 0.295 were respectively in the first to the third ranks and Kohgiluyeh-Buyerahmad, North Khurasan, and Ilam Provinces with $0.081,0.78$, and 0.069 were at the last ranks. The results of VIKOR also indicate that Isfahan, Tehran, and East Azerbaijan with values as 1.129, 1.067, and 0.869 were respectively at the first to the third ranks and South Khorasan, Kohgiluyeh-Buyerahmad, and Ilam provinces respectively with values as $0.636,0.632$, and 0.627 were located at the last ranks. In general, in the TOPSIS method, Tehran has been considered as the most enjoyed and Ilam as the leas enjoyed provinces, while in the VIKOR method, Isfahan has been considered as the most enjoyed and Ilam as the least enjoyed provinces.

According to the enjoyment scores obtained from the TOPSIS and VIKOR methods, using the Density-Based Hierarchical Cluster Analysis method, provinces were classified into three general groups of ultra-enjoyed, semi-enjoyed, and less-enjoyed provinces in terms of the indicators of knowledge-based society and economy. In this classification, Tehran is the only province which is in the ultra-enjoyed cluster, East Azerbaijan, Isfahan, Khorasan Razavi, Khuzestan, and Fars provinces were at the semi-enjoyed cluster, and the other 25 provinces were at the less-enjoyed cluster. The results of leveling provinces indicate that provinces are located in heterogeneous and imbalance conditions. Therefore, regarding spatial analysis of provinces in Iran in terms of investigated indicators, the mentioned provinces can be respectively prioritized at less-enjoyed, semi-enjoyed, and ultra-enjoyed levels for developing indictors of the knowledge-based society and economy.

The results are consistent with the realities of development of provinces to a great extent in such a way that Tehran, due to its status as the administrative-political province and East Azerbaijan, Isfahan, Khorasan Razavi, Khuzestan provinces with their industrial performance and functions, have underlying knowledge-based indictors; therefore, they have high scores and ranks in each of the four components of the knowledge-based society and economy. On the contrary, other provinces, due to their weakness in fundamental development structure, knowledge-based components in them are relatively at lower levels and with lower cluster, they are located in the third cluster.

\section{Offers}

-Balancing the spatial organization of the country;

-The development of knowledge through "investment in the development of superior technology", "growth based on industry leading technology", "relying on high-skilled labor", "plan and organize new institutions, government industry and their relationship with each other";

-Indicators of the government to balance community and knowledge-based economy in the region;

-The government to improve the quality of regulations and rules to protect the security of individual property rights to promote knowledge-based economy;

-Government's attention to the efficiency of government spending researchers in the field of research and development costs;

-Huge investment in infrastructure and urban facilities based on existing capabilities in provincial cities.

-Strengthening and expanding knowledge-based society and economy indicators in the region are low in priority order from the lowest to the highest rank to modify the distribution criteria for the development of small provinces are as follows (Table 7):

-The development of indicators of "human capital", respectively, in South Khorasan province, Semnan, North Khorasan, Kohgiloyeh-Buyerahmad, Chaharmahal-Bakhtiari, Ilam, Tehran, Qom, Bushehr, Qazvin, Sistan-Baluchestan, Hormozgan, Tehran, Yazd, Ardabil, Central , Gulistan, Hamedan, Lorestan, Kermanshah;

-The development of indicators of "economic structure", respectively, in the provinces of Ilam, Ardebil, North Khorasan, kohgiloyeh, Chaharmahal-Bakhtiari, Zanjan, Semnan, Tehran, Khorasan, Hamedan, Qom, Qazvin, Sistan-Baluchestan, Kermanshah, Bushehr, Central Lorestan;

-The development of trade "systems of innovation" in order Kohgiloyeh-Buyerahmadin the provinces of Kurdistan, Khorasan, Ilam, South Khorasan, Lorestan, Golestan, Sistan-Baluchestan, Hamedan, Zanjan, Kermanshah, Chaharmahal-Bakhtiari, West Azarbaijan, Ardabil, Kerman, Hormozgan;

-The development of indicators of "ICT" respectively in the provinces of North Khorasan, Zanjan, Ilam, Chaharmahal-Bakhtiari, Qazvin, Hamedan, Qom, Markazi, Kohgiloyeh-Buyerahmad, Ardebil, Bushehr, Semnan, Lorestan, Hormozgan, Kordestan, Kermanshah, Alborz, Gilan, Golestan, Kerman, Sistan-Baluchestan, West Azerbaijan. 


\section{References}

Asgharpour, M. (2006). Multiple attribute decision making (4th ed.). Tehran: University of Tehran press.

Bashiri, M. (2011). A new approach to multiple attribute decision making. Tehran: University of Shahed press.

Business Cluster Development Foundation Asia. (n.d.). Retrieved from http://www.abcdfoundation.com/

Crevoisier, O., \& Camagni, R. (2000). Les Milieux urbains: Innovation, systemes de production et ancrage [The Urban Environment: Innovation, Production Systems and Anchorage]. Neuchatel, EDES. Retrieved from https://libra.unine.ch/Publications/Par-ann\%E9e/Y-2000/6775

Database equity shares. (n.d.). Retrieved from http://www.vase.ir/

David, P. A., \& Foray, D. (2002). An introduction to the economy of the knowledge society. International Science Journal, 54(171), 9-23. http://dx.doi.org/10.1111/1468-2451.00355

Glaeser, E. (2005). Review of Richard Florida's the Rise of the Creative Class. Regional Science and Urban Economics, 35(5), 593-659. http://dx.doi.org/10.1016/j.regsciurbeco.2005.01.005

Internet National Development Management Center. (n.d.). Retrieved from http://www.iriu.ir/matma/

Iranian National Standards Organization. (n.d.). Retrieved from http://www.isiri.org/

Isaksen, A., \& Onsanger, K. (2010). Regions, networks and innovative performance: The case of knowledge-intensive industries in Norway. European Urban and Regional Studies, 17(3), 227-243. http://dx.doi.org/10.1177/0969776409356217

Islamic Republic of Iran Customs Administration. (n.d.). Retrieved from http://www.irica.gov.ir/

Jacobs, J. (1961). The death and life of great American cities. New York: Random House press.

Kalantari, K. (2007). Processing and analysis of data on socio-economic research. Farhang Saba press, Tehran.

Mendez, R., \& Moral, S. (2010). Spanish cities in the knowledge economy: Theoretical debates and empirical evidence. European Urban and Regional Studies, 18(2), 136-155. http://dx.doi.org/10.1177/0969776410381039

Moulaert, F., \& Nussbaumer, R. (2005). The social region. European Urban and Regional Studies, 12(1), 45-64. http://dx.doi.org/10.1177/0969776405048500

Nastaran, M. (2009). Application of TOPSIS to analyze and prioritize the sustainable development of urban areas (Case Study: Isfahan's urban areas). Geography and Environmental Planning, 38(2), 83-100. Retrieved from http://fa.journals.sid.ir/ViewPaper.aspx?ID=116671

National Network Statistics. (n.d.). Retrieved from http://www.sci.org.ir/

OECD. (1996). The knowledge Based Economy. Paris: OECD.

OECD. (2001). The New Economy: Beyond the Hype. Paris: OECD.

Sayadi, M. K., Heydari, M., \& Shahanaghi, K. (2009). Extension of VIKOR method for decision making problem with interval numbers. Applied Mathematical Modelling, 33(5), 2257-2262. http://dx.doi.org/10.1016/j.apm.2008.06.002

Simmie, J., \& Strambach, S. (2006). The contribution of KIBS to innovation in cities: An evolutionary and institutional perspective. Journal of Knowledge Management, 10(5), 26-40. http://dx.doi.org/10.1108/13673270610691152

Statistical Center of Iran. (2011). The overall results of the general census of population and housing, the vice president for strategic planning and control. Retrieved from http://www.amar.org.ir/Portals/0/sarshomari90/n_sarshomari90_2.pdf

Vahidi, P. (2001). Knowledge-based economy and the role of research and development in it, Conference on Challenges and prospects of development of Iran. Tehran. Retrieved from March, 2001, $\mathrm{http} / / / \mathrm{www} . j o b p o r t a l . i r / \mathrm{s} 1 /$ Default.aspx?ID=9_3_917_1_1723

Webster, F. (2002). Theories of the Information Society. New York: Routledge press. http://dx.doi.org/10.4324/9780203426265 


\section{Note}

Note 1. Organisation for Economic Co-operation and Development.

\section{Copyrights}

Copyright for this article is retained by the author(s), with first publication rights granted to the journal.

This is an open-access article distributed under the terms and conditions of the Creative Commons Attribution license (http://creativecommons.org/licenses/by/3.0/). 